\title{
Candidate epitopes for measurement of hCG and related molecules: the second ISOBM TD-7 workshop
}

\author{
P. Berger • E. Paus • P. M. Hemken • C. Sturgeon • W. W. Stewart • \\ J. P. Skinner • L. C. Harwick • S. C. Saldana • C. S. Ramsay • \\ K. R. Rupprecht • K. H. Olsen • J.-M. Bidart • U.-H. Stenman • \\ on behalf of the members of the ISOBM TD-7 Workshop on hCG and Related Molecules
}

Received: 17 May 2013 / Accepted: 1 July 2013 / Published online: 26 September 2013

(C) The Author(s) 2013. This article is published with open access at Springerlink.com

\begin{abstract}
Participants of the Second International Workshop (WS) on human chorionic gonadotropin (hCG) of the International Society of Oncology and Biomarkers Tissue Differentiation 7 (ISOBM TD-7) have characterized in detail a panel of 69 antibodies (Abs) directed against hCG and hCG-related variants that were submitted by eight companies and research groups. Specificities of the Abs were determined using the First WHO International Reference Reagents for six hCG variants, i.e., hCG, hCGn, hCG $\beta$, hCG $\beta$ n, hCG $\beta c f$, and $\mathrm{hCG} \alpha$, which are calibrated in SI units, and hLH. Molecular epitope localizations were assigned to the ISOBM-mAbs by comparing ISOBM-Ab specificity, sandwich compatibility, and mutual inhibition profiles, to those of 17 reference monoclonal (m)Abs of known molecular epitope specificities. It
\end{abstract}

The International Society of Oncology and Biomarkers Tissue Differentiation (TD)-7 Workshop on hCG and Related Molecules.

Electronic supplementary material The online version of this article (doi:10.1007/s13277-013-0994-6) contains supplementary material, which is available to authorized users.

\author{
P. Berger $(\bowtie)$ \\ Institute for Biomedical Aging Research, University of Innsbruck, \\ Rennweg 10, A6020 Innsbruck, Austria \\ e-mail: peter.berger@uibk.ac.at \\ E. Paus $\cdot$ K. H. Olsen \\ Department of Medical Biochemistry at Radiumhospitalet, Oslo \\ University Hospital, Oslo, Norway \\ P. M. Hemken - J. P. Skinner - L. C. Harwick - S. C. Saldana • \\ C. S. Ramsay $\cdot$ K. R. Rupprecht \\ Diagnostic Research and Development, Abbott Diagnostics, \\ Abbott Park, IL, USA \\ C. Sturgeon \\ Department of Clinical Biochemistry, Royal Infirmary, UK \\ NEQAS for Peptide Hormones, Edinburgh, UK
}

appeared that 48 Abs recognized hCG $\beta-, 8$ hCG $\alpha$-, and 13 $\alpha \beta$-heterodimer-specific epitopes. Twenty-seven mAbs were of pan hCG specificity, two thereof with no $(<0.1 \%$; epitope $\left.\beta_{1}\right), 12$ with low $\left(<1.0 \%\right.$; epitopes $\left.\beta_{2 / 4}\right)$, and 13 with high $\left(>>1 \%\right.$; epitopes $\left.\beta_{3 / 5}\right)$ hLH cross-reactivity. The majority of $\mathrm{hCG} \beta$ epitopes recognized were located in two major antigenic domains, one on the peptide chain of the tips of $\beta$-sheet loops 1 and 3 (epitopes $\beta_{2-6} ; 27 \mathrm{mAbs}$ ) and the second around the cystine knot (e.g., epitopes $\beta_{1}, \beta_{7}$, and $\left.\beta_{10} ; 9 \mathrm{mAbs}\right)$. Four mAbs recognized epitopes on hCG $\beta$ cf-only (e.g., epitopes $\beta_{11}$ and $\beta_{13}$ ) and six mAbs epitopes on the remote hCG $\beta$ carboxyl-terminal peptide (epitopes $\beta_{8}$ and $\beta_{9}$ corresponding to amino acids $135-144$ and 111-116, respectively). For routine diagnostic measurements, methods are used that either

W. W. Stewart

Department of Immunology, Ninewells Hospital and Medical School, Dundee, UK

J.-M. Bidart

Department of Clinical Biology, Institut Gustave-Roussy, Villejuif, France

U.-H. Stenman

Department of Clinical Chemistry, Helsinki University Central Hospital, Helsinki, Finland 
detect hCG-only, hCG $\beta$-only, or hCG together with hCG $\beta$ or hCG together with hCG $\beta$ and hCG $\beta$ cf. Sandwich assays that measure hCG plus hCG $\beta$ and eventually hCG $\beta$ cf should recognize the protein backbone of the analytes preferably on an equimolar basis, should not cross-react with hLH and not be susceptible to blunting of signal by nonmeasured variants like hCG $\beta$ cf. Such assays can be constructed using pairs of mAbs directed against the cystine knot-associated epitope $\beta_{1}$ (Asp10, Asp60, and Gln89) in combination with epitopes $\beta_{2}$ or $\beta_{4}$ located at the top of $\beta$-sheet loops $1+3$ of hCG $\beta$ involving aa hCG $\beta 20-25+68-77$. In summary, the results of the First and Second ISOBM TD-7 WSs on hCG provide the basis for harmonization of specificities and epitopes of mAbs to be used in multifunctional and selective diagnostic hCG methods for different clinical purposes.

Keywords hCG variants measurement · Antibody standardization · Epitope standardization · International standards for hCG $\cdot$ hCG IRR

\section{Objective}

Improving between method comparability for measurement of the heterogeneous glycoprotein hCG requires harmonization of epitopes of the Abs used and broad consensus about assay specificity. To address this, the Second International Society of Oncology and Biomarkers Tissue Differentiation 7 (ISOBM TD-7) Workshop (WS) by a three-step algorithm characterized and epitope typed $69 \mathrm{Abs}$ directed against hCG and variants submitted by diagnostic companies and research groups. The results of this WS in combination with those of the First WS enable recommendations to be made regarding epitope combinations to be used for the design of immunoassays for hCG and its variants [1].

\section{Introduction}

Physiology, protein structure, and posttranslational protein backbone variants of hCG

The glycoprotein hormone hCG is essential for maintaining pregnancy. Physiologically, it is produced and secreted by the placental trophoblast and pathophysiologically by trophoblastic cancers and by germ cell tumors of the testis and ovary [2].

$\mathrm{hCG}$ is a protein heterodimer consisting of $\mathrm{hCG} \alpha$ noncovalently linked to the $\mathrm{hCG} \beta$ subunit. As all glycoprotein hormone $(\mathrm{GPH})$ subunits, hCG $\alpha$ and hCG $\beta$ share structural homology with members of the cystine knot growth factor superfamily that includes nerve growth factor, platelet-derived growth factor and transforming growth factor beta [3]. The common structural cystine knot motif consists of two disulfide bridges that link adjacent antiparallel strands of the single peptide chain to form a ring that is axially permeated by a third disulfide bond. This central cystine knot determines the three-dimensional structure of $\mathrm{hCG} \alpha$ and $\mathrm{hCG} \beta$. On one side of the knot, there are two neighboring hairpin-like peptide loops 1 and 3, which, in hCG $\beta$, are stabilized by a disulfide bond between Cys 23 and Cys 72 . The single larger loop 2 is located on the opposite side of the knot [3].

The subunits are noncovalently linked in antiparallel, i.e., a head-to-toe fashion, such that loops $1+3$ of one subunit are adjacent to loop 2 of the other subunit [3]. Loops 1 and 3 of either subunit and the hCG $\beta$ cystine knot, respectively are the most important antigenic regions [1].

The hCG $\beta$ genes have developed from an ancestral LH $\beta$ gene by gene duplications and mutations [4]. The hCG $\beta$ protein is 145 amino acids (aa) in length and encoded by 4 genes and 2 alleles (CG $\beta 6 / 7, C G \beta 3 / 9, C G \beta 5$, and $C G \beta 8)$, while hLH $\beta$ is encoded by a single gene, CG $\beta 4$, on chromosome $19 \mathrm{q} 13.3$. Thus, $\mathrm{hCG} \beta$ and $\mathrm{hLH} \beta$ are highly similar in protein sequence $(>85 \%)$ and are immunologically closely related. Furthermore, LH and hCG activate the same receptor. The major structural difference between $\mathrm{hCG} \beta$ and $\mathrm{hLH} \beta$ is a carboxyl-terminal peptide extension of $\mathrm{hCG} \beta$ (hCG $\beta \mathrm{CTP}$ ) encompassing aa 113-145. hCG $\beta C T P$ evolved through a read-through event due to a mutational loss of the stop codon at the genomic level and the incorporation of a hitherto untranslated gene sequence into the coding region [5]. Antibodies recognizing epitopes on hCG $\beta C T P$ are used in a number of highly specific hCG assays [6]. A single gene on human chromosome 12q21.1-23 encodes the $\alpha$-subunit, which is 92 aa in length and common to all four human GPHs [7].

hCG is heterogeneous with respect to protein backbone structure and carbohydrate content and is best considered as a complex family of hCG variants occurring in body fluids and tissues. The unambiguous nomenclature for the most important hCG forms of the protein backbone developed by the International Federation of Clinical Chemistry (IFCC) Working Group for Standardization of hCG Determinations is used here (Table 1 and Fig. 1) $[1,8,9]$.

\section{Glycosylation isoforms}

hCG subunit folding, assembly, intracellular trafficking, secretion, receptor activation, and half-life in serum is dependent on glycosylation [10]. Both hCG subunits are glycosylated: hCG $\alpha$ contains two N-glycosylation sites at Asn 52 and Asn78 that are either mono-, bi-, or triantennary or are sometimes missing. Most N-linked carbohydrate antennae at Asn13 and Asn30 of hCG $\beta$ are of the bi-antennary type, but malignancyassociated hCG increasingly carries triantennary carbohydrates at Asn30 and fucosylation at Asn13 (Fig. 2). Four putative O-glycosylation sites are located at Ser121 (core-2), 
Table 1 Nomenclature of hCG and hCG-related variants (modified according to [1] with permission)

\begin{tabular}{ll}
\hline Symbol & Molecular definition \\
hCG & Intact $\alpha \beta$ heterodimer, bioactive \\
hCGn & Nicked $\alpha \beta$ heterodimer, nicks in the region of aa hCG $\beta 44-48$ \\
hCG $\beta$ & Intact noncombined free hCG $\beta$-subunit, aa hCG $\beta 1-145$ \\
hCG $\beta \mathrm{n}$ & Nicked hCG $\beta$, nicks in the region of aa hCG $\beta 44-48$ \\
hCG $\beta \mathrm{cf}$ & Core fragment of hCG $\beta$; aa hCG $\beta 6-40$ linked to hCG $\beta 55-92$ \\
hCG $\alpha$ & Noncombined free $\alpha$-subunit of hCG; aa hCG $\alpha 1-92$ \\
Less well-defined hCG variants \\
hCG $\beta C T P$ & Carboxylterminal extension of hCG $\beta$, aa hCG $\beta 109 / 114-145$ \\
-CTPhCG & hCG $\beta$ truncated core hCG, missing most of the hCG $\beta C T P$ (aa hCG $\beta 121-145$ ) \\
-CTPhCG $\beta$ & hCG $\beta$ truncated core hCG $\beta$ (aa hCG $\beta 1-120$ ), missing most of the hCG $\beta C T P$ \\
\hline
\end{tabular}

Ser127 (core-1), Ser132 (core-1), and Ser138 (core-1) on the hCG $\beta C$ TP. The pregnancy associated core-1 glycans on Ser127 and Ser132 are frequently replaced by core- 2 glycans in hCG synthesized in early pregnancy and by tumors [11].

Due to variability in branching of carbohydrate antennae and terminal sialylation (8-15 sialic acids), numerous isoforms exist $[11,12]$. The relative proportions of more extensively glycosylated and terminally sialylated glycosylation variants change with advancing pregnancy, tumor progression, and between different tumors [13-15]. Consequently, acidic variants (av) of hCG (avhCG) produced by testicular cancer [16], by other tumors, and in early pregnancy [13] have very low isoelectric points (pIs) and higher MWs $[15,17,18]$. The expression avhCG, describing hCG with complex extensively terminally sialylated carbohydrate antennae, was later replaced by the term "hyperglycosylated" hCG (hCG-h) [19]. Presently, hCG-h is defined as hCG isoforms carrying a biantennary core-2 O-glycan on Ser132 that is detected by immunoassays using a mAb-designated B152 (Fig. 2) [20].

\section{hCG epitopes}

Elucidation of the three-dimensional structure of hCG [3] provided the basis for assignment of immunologically and

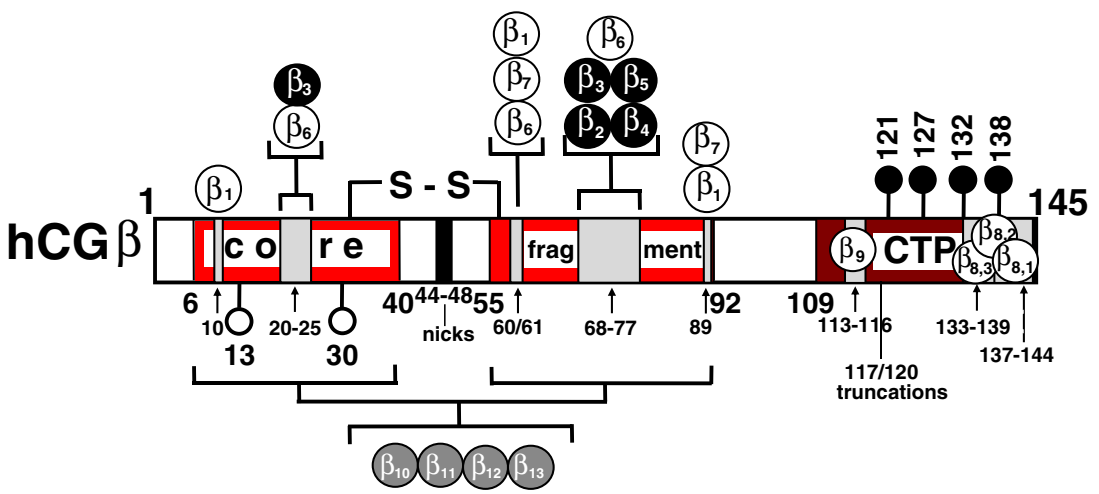

Fig. 1 Schematic representation of human chorionic gonadotropin $\beta$ $(\mathrm{hCG} \beta$ ) protein backbone variants and molecular epitope localizations on assembled and free hCG $\beta$ (amino acids, aa hCG $\beta 1-145$ ), hCG $\beta$ core fragment (hCG $\beta \mathrm{cf}$, aa hCG $\beta 6-40+\beta 55-92$ ), and the carboxylterminal peptide (hCG $\beta$ CTP, aa hCG $\beta 109 / 113-145$ ). Modified according to [1] with permission (INN). Antigenic determinants are diagrammatically represented on the linear aa sequence. Non-assembled hCG $\beta$ carries nine epitopes $\left(\beta_{1}-\beta_{9}\right)$, seven are present also on the hCG $\alpha \beta$-heterodimer $\left(\beta_{1}-\beta_{5}, \beta_{8}, \beta_{9}\right)$, and all, except those on the $\operatorname{hCG} \beta \mathrm{CTP}\left(\beta_{8}, \beta_{9}\right)$, are located within the amino acid sequences (aa) of hCG $\beta c f$. Four additional specific epitopes are present on hCG $\beta$ cf only $\left(\beta_{10}-\beta_{13}\right)$ but not on intact $\mathrm{hCG} \beta$ and hCG. All epitopes that are located on core hCG $\beta$ (aa 1-112) are conformationally dependent and determined by the tertiary protein structure. Important residues contributing to these epitopes at the primary sequence level were identified by selective mutational analyses: Pro24,
Val25, Arg68, Gly71, and Gly75 contribute to epitope $\beta_{3}$, aa Lys20, Glu21, Gln22, Gly75, and Asn77 to free subunit epitope $\beta_{6}$ and Arg68 to structurally overlapping epitopes $\beta_{2}, \beta_{3}, \beta_{4}$, and $\beta_{5}$ [22, 42]. hCG-specific epitope $\beta_{1}$ is built up by cystine-knot associated $\operatorname{Arg} 10$ and $\operatorname{Arg} 60$ and to a minor extent Gln89 as it does in epitope $\beta_{7}$. Asp61 plays a role in free subunit epitopes $\beta_{6}$ and $\beta_{7}$ [43]. Major antigenic regions of hCG $\beta C T P$ are rather linear in nature and determined by the primary structure: aa hCG $\beta 133-144$ comprising epitope $\beta_{8}$, that is substructured into $\beta_{8,1}$ to $\beta_{8,3}$ and aa hCG $\beta 113-116$ corresponding to epitope $\beta_{9}[21,24,29,50,71]$. Numbers represent positions of amino acid residues in the peptide chain. The metabolic product hCG $\beta \mathrm{cf}$ consists of two peptide fragments that are linked via five disulfide bonds (depicted by S-S), and its N-linked carbohydrate antennae are truncated. Open circles $\mathrm{N}$-linked glycans, filled circles O-linked glycans 


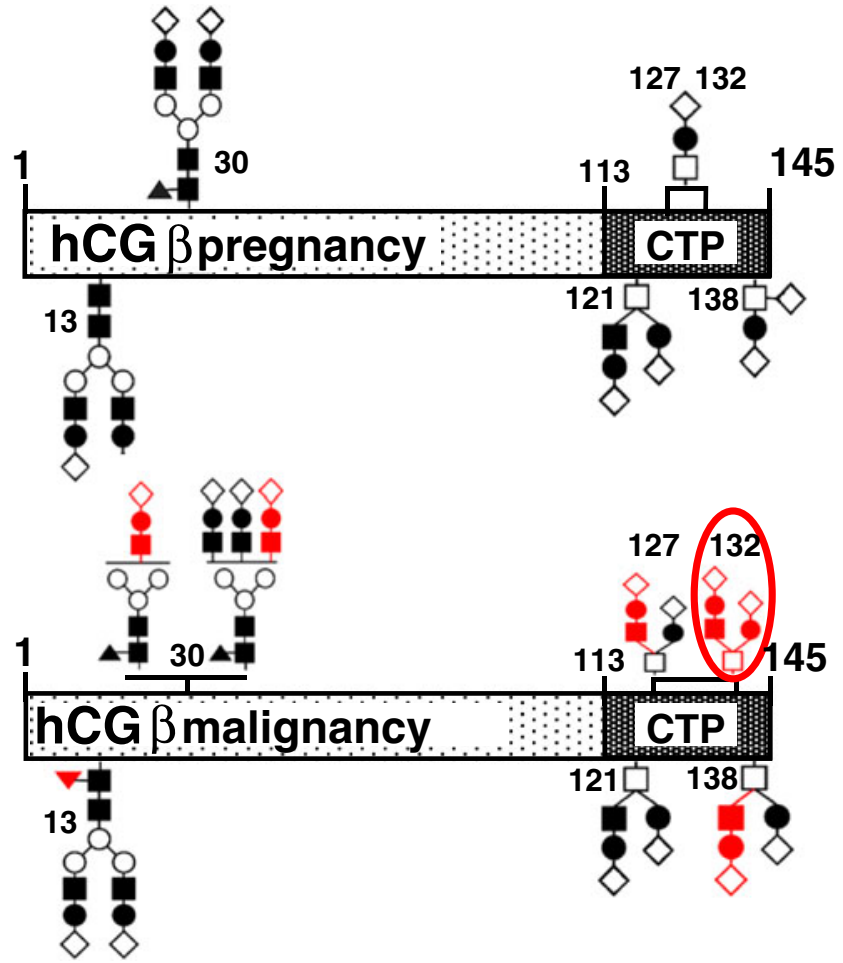

Fig. 2 Glycosylation variants of hCG $\beta$ (according to [11]). In pregnancy-derived $\mathrm{hCG} \beta$, the $\mathrm{N}$-linked carbohydrates are of the biantennary type. O-Glycosylation of hCG $\beta$ at Ser 121 always contains a biantennary core- 2 and at Ser 138 a core- 1 structure with one or two sialic acids. Malignancy-derived hCG and very early pregnancy hCG as compared to middle-to-late pregnancy hCG $\beta$ is characterized by increased content of triantennary complex-type N-linked carbohydrates attached to hCG $\beta$ Asn 30 and fucosylated carbohydrates attached to Asn 13. "Hyperglycosylated" hCG $\beta$ contains an increased proportion of triantennary N-linked carbohydrates (Asn 30); core-2 type O-glycans at Ser 127, Ser 132, and Ser 138; and fucosylated Asn 13-linked glycan. Some glycosylation sites were not glycosylated in some variants (Ser 138, Ser 121, and Asn 13). Immunoassays for hCG-h based on mAb B152 recognize the encircled glycan at Ser 132 and surrounding peptide structure. The major differences in carbohydrate antennae composition between early and mid-to-late pregnancy- and malignancy-derived hCG are depicted in red. Filled square GlcNAc, filled diamond Fuc, empty square GalNAc, empty circle Man, filled circle Gal, empty diamond $\mathrm{NeuAc}$

biologically important domains to the molecular surface of hCG and hCG-related molecules. Several strategies were pursued to resolve epitope distribution and arrangement as well as identification of immunodominant regions. Epitope localization and sharing of epitopes among hCG, hCGvariants, subunits, and related hormones like LH and subunits were determined using molecular chimeras, hCG metabolites, homologous and heterologous glycoprotein hormones and subunits, chemically modified hormones, proteolytic hormone fragments and synthetic peptides, including peptide scanning, and most importantly by site-specific mutagenesis of hCG $\beta$. It is important to mention that in three independent laboratories with different sets of mAbs and analytical techniques similar epitopes and antigenic domains were defined (for reviews, see [1,21].

In previous studies, 26 epitopes on hCG and hCG-related molecules were defined (for reviews, see [1, 20, 22]). Sixteen epitopes are located on the intact holo hormone hCG (epitopes $\beta_{1}-\beta_{5}, \beta_{8}$, and $\alpha_{9} ; \alpha_{1}-\alpha_{5} ;$ and $\mathrm{c}_{1}-\mathrm{c}_{4}$ ). Seven of these are present on both free and assembled hCG $\beta\left(\beta_{1}-\beta_{5}, \beta_{8}\right.$, and $\alpha_{9}$; Fig. 1 and Table 2).

Antibodies against epitopes $\beta_{1}-\beta_{5}$ recognize a wide range of hCG and hCG $\beta$ variants (pan hCG-mAbs), including $\mathrm{hCG}+\mathrm{hCG}+\mathrm{hCG} \beta+\mathrm{hCG} \beta \mathrm{n}+\mathrm{hCG} \beta \mathrm{cf}$. In a first step, epitopes recognized by these mAbs can be discerned by their cross-reactivity with hLH or hLH $\beta$ : Abs directed against (1) epitope $\beta_{1}$ have no $(<0.1 \%)$, (2) epitopes $\beta_{2}$ and $\beta_{4}<1 \%$, and (3) epitopes $\beta_{3}$ and $\beta_{5}>>1 \% \mathrm{hLH}$ cross-reactivity. Epitopes $\beta_{1}-\beta_{5}$ are distributed among two antigenic domains: (1) the cystine knot (epitope $\beta_{1}$ ) and (2) hCG $\beta$ loops $1+3$ comprising the neighbouring epitopes $\beta_{2}-\beta_{6}$. Epitopes $\beta_{8}$ and $\beta_{9}$ are located on the hCG $\beta$ CTP and by definition are specific for hCG and hCG $\beta[1,23,24]$.

A number of epitopes are of restricted variant specificity. Abs against such epitopes are useful for variant-selective immunoassays designed to measure $\mathrm{hCG}, \mathrm{hCG}+\mathrm{hCGn}$, $\mathrm{hCG} \beta, \mathrm{hCG} \beta+\mathrm{hCG} \beta \mathrm{cf}, \mathrm{hCG} \beta \mathrm{cf}$, or $\mathrm{hCG} \alpha$, respectively, in the presence of excess of other hCG protein backbone variants and GPHs.

Epitopes $\beta_{6}$ (hCG $\beta$ loops $1+3$ related) and $\beta_{7}$ (cystine knot related) are shared by free $\mathrm{hCG} \beta$ and hCG $\beta \mathrm{cf}$ but not by holo-hCG. Epitope $\beta_{14}$, which is related to the core region of hCG $\beta$ (amino acids 1-112) and maybe cystine knotrelated, was defined in the First ISOBM WS. It is specific for free hCG $\beta$ and not shared by hCG $\beta \mathrm{cf}[1]$. Four hCG $\beta$ cfspecific epitopes $\beta_{10}-\beta_{13}$ (of which $\beta_{10}$ and $\beta_{12}$ probably are hCG $\beta$ cystine knot-related, $\mathrm{PB}$ unpublished data) are not present on hCG $\beta$, hCG $\beta \mathrm{n}$, hCG, hCGn, or on $\mathrm{hLH} / \mathrm{hLH} \beta / \mathrm{hLH} \beta \mathrm{cf}$. Two epitopes, $\alpha_{6}$ (hCG $\alpha$ loop 2 related) and $\alpha_{7}$ (hCG $\alpha$ carboxyl-terminal related), are specific for nonassembled $\mathrm{hCG} \alpha$.

Some additional Abs recognize epitopes defined only broadly at the molecular level, e.g., additional c- or $\beta$ mAbs. Within antigenic domains there seem to be epitopes that remain to be defined more precisely [1].

Algorithm to define hCG epitopes of ISOBM mAbs (INN)

For the Second ISOBM TD-7 WS on hCG, a previously reported epitope mapping algorithm [22], which was also used in similar form in the First ISOBM TD-7 hCG WS [1] has been further refined to reliably characterize the specificities and epitopes of the 69 ISOBM-Abs. This three-step algorithm involves: 
Table 2 hCG reference-mAbs: molecular localization of epitopes and specificity patterns (modified according to [1], with permission)

\begin{tabular}{|c|c|c|c|c|c|c|c|c|c|c|c|c|c|c|}
\hline \multicolumn{2}{|c|}{ Epitopes } & \multicolumn{11}{|c|}{ mAb Specificities } & \multicolumn{2}{|c|}{ Reference mAbs ${ }^{1)}$} \\
\hline $\begin{array}{c}\text { Code } \\
\beta \text {-mAbs }\end{array}$ & $\begin{array}{c}\text { Molecular } \\
\text { Localization }\end{array}$ & hCG & hCG $\beta$ & hCG $\beta$ cf & hCGn & hCG $\beta n$ & $\begin{array}{l}\text {-CTP } \\
\text { hCG }\end{array}$ & $\begin{array}{l}\text {-CTP } \\
\text { hCG } \beta\end{array}$ & $\mathrm{hLH}$ & $\mathrm{hLH} \beta$ & $\begin{array}{l}\text { hFSH } \\
\text { hTSH }\end{array}$ & GPH $\alpha$ & mAb-Code & Characteristics \\
\hline$\beta_{1}$ & $\begin{array}{c}\text { Cystine knot } \\
\text { hCG } 10+60+89\end{array}$ & & & & & & & & & & & & $\begin{array}{l}\text { ISOBM-435/ } \\
\text { INN-hCG-2 }\end{array}$ & highly specific \\
\hline$\beta_{2}$ & & & & & & & & & $<1 \%$ & $<1 \%$ & & & 449/INN-hCG-22 & \\
\hline$\beta_{3}$ & hCG $\beta$ loops $1+3$ & & & & & & & & & & & & 441/INN-bLH-1 & pan hCG $\beta$ \\
\hline$\beta_{4}$ & $\begin{array}{c}\text { hCG } 320-25+ \\
68-77\end{array}$ & & & & & & & & $<1 \%$ & $<1 \%$ & & & 445/INN-hCG-24 & \\
\hline$\beta_{5}$ & & & & & & & & & & & & & 442/INN-hCG-58 & \\
\hline$\beta_{6}$ & & & & & & ? & & ? & & & & & 437/INN-hCG-64 & free $\mathrm{hCG}$ \\
\hline$\beta_{7}$ & $\begin{array}{l}\text { Cystine knot } \\
\text { hCG } 61+89\end{array}$ & & & & & & & & & & & & 439/INN-hCG-68 & ree nomp \\
\hline$\beta_{8}$ & hCG $135-145$ & & & & & & & & & & & & $450 / \mathrm{h} 54$ & hCGBCTP \\
\hline$\beta_{9}$ & hCG及111-116 & & & & & & & & & & & & $--/$ FB-12 & 19 \\
\hline$\beta_{10}$ & & & & & & & & & & & & & 448/INN-hCG-103 & \\
\hline$\beta_{11}$ & hCG $\beta c f$ & & & & & & & & & & & & \begin{tabular}{|l|}
$--/ / N N-h C G-104$ \\
444/INN-hCG-106
\end{tabular} & $\begin{array}{c}\text { hCG } \beta c f \\
\text { highly specific }\end{array}$ \\
\hline$\beta_{12}$ & & & & & & & & & & & & & --/INN-hCG-105 & \\
\hline$\beta_{13}$ & & & & & & & & & & & & & 448/INN-hCG-112 & \\
\hline
\end{tabular}

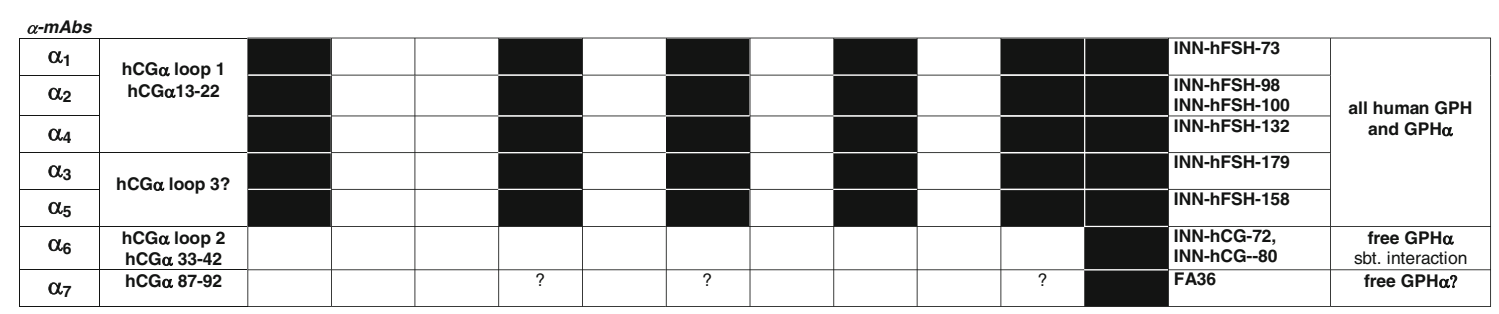

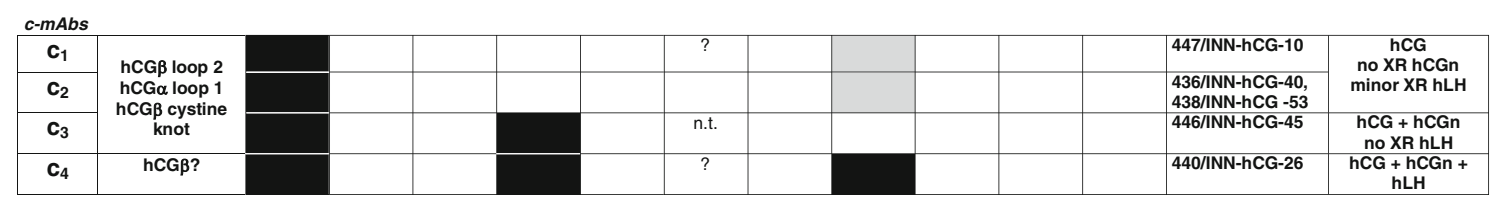

$G P H \alpha$ glycoprotein hormone alpha subunit, n.t. not tested

a "INN-" reference mAbs can be obtained from the author (P.B.); filled squares, strong reactivity; open squares, no reactivity; gray squares, minor reactivity

1. Determination of intraspecies $\mathrm{Ab}$ specificities with $\mathrm{hCG}$, hCG-related variants [six First International Reference Reagents (IRR) preparations], hLH and synthetic hCG $\beta C T P$ peptides to enable grouping of the mAbs according to their main specificities ( $\alpha-, \beta-$, and $c-m A b s)$, and tentative assignment of epitopes by comparing specificity profiles to those of reference mAbs with known epitope recognition

2. Confirmation of epitope recognition and spatial arrangement of epitopes using sandwich assays with mutual antigen recognition or inhibition by pairs of $\mathrm{mAbs}$ to provide information about epitope disparity or identity/vicinity

3. Cross-referencing of the ISOBM-Abs' reaction profiles in specificity and sandwich assays to those of reference mAbs recognizing previously defined epitopes.

This approach frequently enabled definitive assignment of epitopes at the molecular level. In rare cases where no exact molecular localization could be determined due to the lack of appropriate reference mAbs, additional circumstantial evidence, e.g., mutual steric inhibition in simultaneous antigen recognition with mAbs of known epitope localization or recognition of breakdown products like hCG $\beta$ cf or inter-species cross-reactivity, was used to elucidate the epitope's antigenic domain [1].

\section{Materials and methods}

ISOBM-Abs: codes and descriptions

Sixty-nine ISOBM-TD-7 Abs were submitted by eight participants to Dr. Kjell Nustad at the Central Laboratory, Norwegian Radium Hospital (NRH), Oslo, Norway (see Table 7 in Appendix). The Abs were assigned code numbers ISOBM382 to 450. The panel contained (1) $42 \mathrm{Abs}$ to be tested for molecular epitope recognition, (2) $10 \mathrm{mAbs}$ that were previously specificity- and epitope-typed in the First ISOBM TD-7 WS on hCG as blinded internal controls: ISOBM-403 is identical to reference $\mathrm{mAb}-435$ and corresponds to ISOBM-265 and ISOBM-274 in the First WS, ISOBM-411 is identical to 275 (First WS), ISOBM-415 to -281 ; ISOBM-416 to -273 ; ISOBM-417 to -276 ; ISOBM-418 to -280 ; ISOBM-419 to 271; ISOBM-420 to -264 and -277 ; ISOBM-422 to -272 , and 
ISOBM-424 to -279 [1] (Appendix); and (3) 17 reference mAbs (ISOBM-434-450) of known specificity and epitope recognition provided by Dr. Peter Berger from the Institute for Biomedical Aging Research, Innsbruck (INN), Austria. The hybridomas producing mouse reference mAbs (INNmAbs) against hCG, hCG $\beta$, hCG $\beta c f$, and hCG $\beta C T P$ were established as previously described [23, 25-31] and specificity, affinity, and epitope analyses by a panel of immunochemical techniques (for reviews, see $[1,22]$ ).

The 17 reference mAbs were directed against 15 epitopes on hCG and hCG-related molecules (Table 2) (for reviews, see $[1,22])$. Ten epitopes were located on intact hCG (epitopes $\beta_{1}-\beta_{5}$ and $\beta_{8} ; c_{1}-c_{4}$ ), and six of these shared by $h C G \beta$ $\left(\beta_{1}-\beta_{5}\right.$, and $\left.\beta_{8}\right)$. Two Abs recognized epitopes on hCG $\beta$ plus hCG $\beta$ n plus hCG $\beta$ cf $\left(\beta_{6}\right.$ and $\left.\beta_{7}\right)$. Three reference mAbs against epitopes $\beta_{10}, \beta_{11}$, and $\beta_{13}$ recognized exclusively hCG $\beta$ cf. MAb FB12 recognizing hCG $\beta$ CTP epitope $\beta_{9}$ [32], ISOBM-278 (epitope ( $\beta_{8}$ type $1, \beta_{8,1}$ ) ISOBM-277 (epitope $\beta_{8}$ type $2, \beta_{8,2}$ ) and ISOBM-267 (epitope $\beta_{14}$ ) [1] were additionally used as control reagents. No reference or control mAbs for epitopes $\alpha_{1}-\alpha_{7}, \beta_{12}$, and $\beta_{8 / 3}$ ) were applied in the specificity and epitope typing experiments.

The Abs were checked for purity by sodium dodecyl sulfate polyacrylamide gel electrophoresis (SDS-PAGE), the protein content determined by measuring the absorbance at $280 \mathrm{~nm}(1 \mathrm{mg} / \mathrm{mL}=1.43)$, aliquoted and $1 \mathrm{mg}$ of each sent to the laboratories of the workshop participants performing the experimental work: Dr. Phil Hemken, Diagnostic Research and Development, Abbott Diagnostics (ABB); Dr. Elisabeth Paus, Radiumhospitalet, Oslo University Hospital, (NRH); Dr. Ulf-Håkan Stenman (UHS), Helsinki University Central Hospital; and Dr. Wilson Stewart, Ninewells Hospital and Medical School, Dundee (NHD).

First international reference reagents for $\mathrm{hCG}$ and $\mathrm{hCG}$ variants

The new international standards for hCG, nicked hCG (hCGn), $\mathrm{hCG} \alpha, \mathrm{hCG} \beta, \mathrm{hCG} \beta \mathrm{n}$, and $\mathrm{hCG} \beta \mathrm{cf}$ were purified and characterized by the IFCC Working Group for Standardization of hCG Determinations [9] and adopted by the WHO as the First IRR for hCG and related variants [33]. The material is intended for use in the calibration of immunoassays in substance concentrations, i.e., moles per liter [6]. One milligram each of the six First IRRs for hCG and related molecules were kindly supplied by the NIBSC (Dr. Catharine Sturgeon, CS) to each of the participants and used to characterize the 69 ISOBM-Abs (Table 3).

For iodination, FRET and BIAcore ${ }^{\circledR}$ specificity and affinity determinations the carrier-free frozen concentrates (FC) of the six First IRRs were used: hCG (FC 99/688), hCGn (FC 99/642), hCG $\beta$ (FC 99/650), hCG $\beta$ n (FC 99/ 692), hCG $\beta$ cf (FC 99/708), and hCG $\alpha$ (FC 99/720).
Table 3 The WHO $1^{\text {st }}$ IRRs for hCG and related variants and $5^{\text {th }}$ IS for hCG

\begin{tabular}{|c|c|c|}
\hline Symbol & WHO code & Content/ampoule \\
\hline hCG & $5^{\text {th }}$ IS $07 / 364^{\mathrm{a}}$ & $0.39 \mathrm{nmol}$ or $179 \mathrm{IU}$ \\
\hline hCG & $1^{\text {st }}$ IRR 99/688 & $1.88 \mathrm{nmol}$ \\
\hline hCGn & $1^{\text {st }}$ IRR 99/642 & $0.78 \mathrm{nmol}$ \\
\hline $\mathrm{hCG} \beta$ & $1^{\text {st }}$ IRR $99 / 650$ & $0.84 \mathrm{nmol}$ \\
\hline hCG $\beta n$ & $1^{\text {st }}$ IRR 99/692 & $0.88 \mathrm{nmol}$ \\
\hline hCG $\beta \mathrm{cf}$ & $1^{\text {st }}$ IRR 99/708 & $0.33 \mathrm{nmol}$ \\
\hline $\mathrm{hCG} \alpha$ & $1^{\text {st }}$ IRR 99/720 & $1.02 \mathrm{nmol}$ \\
\hline
\end{tabular}

${ }^{\text {a }}$ The $1^{\text {st }}$ IRR 99/688 for hCG has been adopted as the new $5^{\text {th }}$ IS $07 /$ 364 for hCG

Other hormones and peptides

Human LH (hLH-I-1) AFP4345B for iodination was obtained from National Hormone \& Peptide Program, USA. The peptide hCG $\beta C T P 135-145$, PGPSDTPILPQ, was ordered from AltaBioscience, UK. The peptide hCG $\beta$ CTP109-145, TCD DPRFQDSSSSKAPPPSLPSPSRLPGPSDTPILPQ, was provided by Dr. Jean-Michel Bidart.

Biochemical characterization of the mAbs (ABB, NRH)

The mAbs were biochemically characterized by gel permeation chromatography-high performance chromatography (GPC-HPLC; ABB; Online Resource 1), SDS-PAGE under reducing (ABB; Online Resource 2 ) and non-reducing conditions (NRH; Online Resource 3), Ab isotyping (ABB, NRH; Online Resource 4), isoelectric focusing (IEF; ABB; Online Resource 5), and finally mass spectrometry (MS; ABB; Online Resource 6), which was utilized for further characterization of $\mathrm{Ab}$ samples where double heavy or double light chain bands were observed using SDS-PAGE testing.

Determination of $A b$ specificity, affinity, and epitope localization (ABB, NRH)

The main specificity profiles of mAbs were determined (1) by direct binding RIA (DB-RIA) with ${ }^{125}$ I-labeled hormones and hormone fragments with excess $\mathrm{Ab}$ (Online Resources 7, 8 ) and (2) with competitive ligand analysis (CLA), a RIA format, wherein the binding between ${ }^{125} \mathrm{I}-\mathrm{hCG}$ and serial diluted Abs is competed with fixed concentrations of the six First IRRs of hCG and hCG-related molecules and hLH (75/552), respectively (Online Resource 9). Cross-reactivity of the ISOBM-Abs with hLH was determined by titration RIA (NRH) by comparing titers of ${ }^{125}$ I-labeled hCG versus

${ }^{125}$ I-labeled LH (Online Resource 10). Epitope recognition on the hCG $\beta$ CTP by ISOBM-Abs was evaluated by competitive RIA with synthetic peptides (NRH; Online Resource 
11). Ab affinities were determined by Forster Resonance Energy Transfer (FRET) (ABB; Online Resource 12) and by BIAcore ${ }^{\circledR}$ (NHD; Online Resource 13). For elucidation of the spatial arrangement of epitopes, Ab compatibility in antigen recognition was evaluated by sandwich RIA (NRH; Online Resource 14).

\section{Results}

Biochemical characterization of the mAbs (ABB; NRH)

\section{Gel permeation chromatography-high performance chromatography $(A B B)$}

The homogeneity of the mAbs determined by GPC ranged from 57 to $99 \%$ with varying degrees of aggregation and low MW contaminants (Fig. 3a; Online Resource 15). All samples exhibited low MW peaks possibly caused by buffer components (azide, citrate, DTT, etc.).

\section{Sodium dodecyl sulfate polyacrylamide gel electrophoresis} (NRH, ABB)

SDS-PAGE analysis was performed under nonreducing (Online Resource 16a; NRH) and reducing conditions (Online Resource 16b; ABB). The purity of the mAbs determined as the proportion of heavy and light chains relative to all protein bands ranged from 84 to $100 \%$ (Online Resource 16b). An example for slight albumin impurity is shown in Fig. 3b. The appearance of double chains could be due to glycosylation differences [34, 35], amino acid residue issues [34, 35], or the presence of more than one $\mathrm{Ab}$ in the sample (Online Resource 16b).

\section{Isoelectric focusing $(A B B)$}

The isoelectric point $(\mathrm{p} I)$ of the Abs ranged from 5.0 to 7.7 (Fig. 3c; Online Resource 17). Those for ISOBM-397, ISOBM-418, and ISOBM-431 could not be determined. The smearing or absence of bands was probably due to low solubility of these Abs at the low ion strength in IEF.

\section{Isotyping $(A B B)$}

Isotyping was performed on samples displaying double heavy or light chains in SDS-PAGE analysis (Table 4).

\section{Mass spectrometry analysis (ABB)}

Apart from the following exceptions most ISOBM-Abs gave expected results. ISOBM-382 had double light chains, and more than one group of heavy chains present following deglycosylation, suggesting presence of two mAbs. ISOBM385 had two groups of heavy chains due to glycosylation and ISOBM-388 two nonglycosylated light chains due to amino acid residue differences. ISOBM-400 and ISOBM-406 had more than one group of light chains due to differences in a

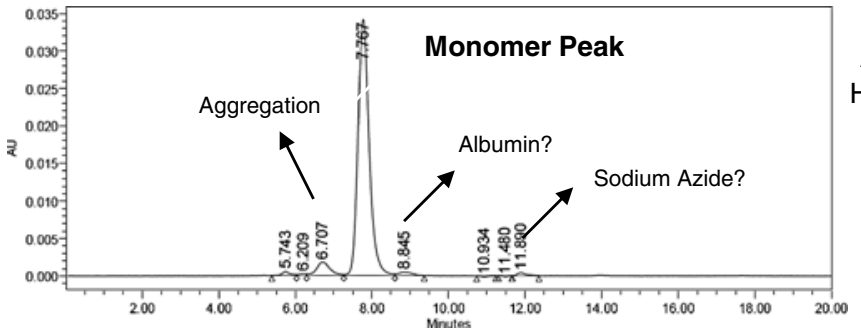

Fig. 3 Biochemical characterization of ISOBM-435 by GPC-HPLC (a), reduced SDS-PAGE (b), and IEF (c). a Percent purity by GPCHPLC analysis is $96 \%$ with $7 \%$ aggregation and a small amount $(2 \%)$ of low molecular weight $(L M W)$ contaminants. The LMW material could be sodium azide and residual albumin, but this was not confirmed. b Reduced SDS-PAGE analysis shows a combined heavy and light chain purity of $96 \%$. The first strip has been enhanced to increase
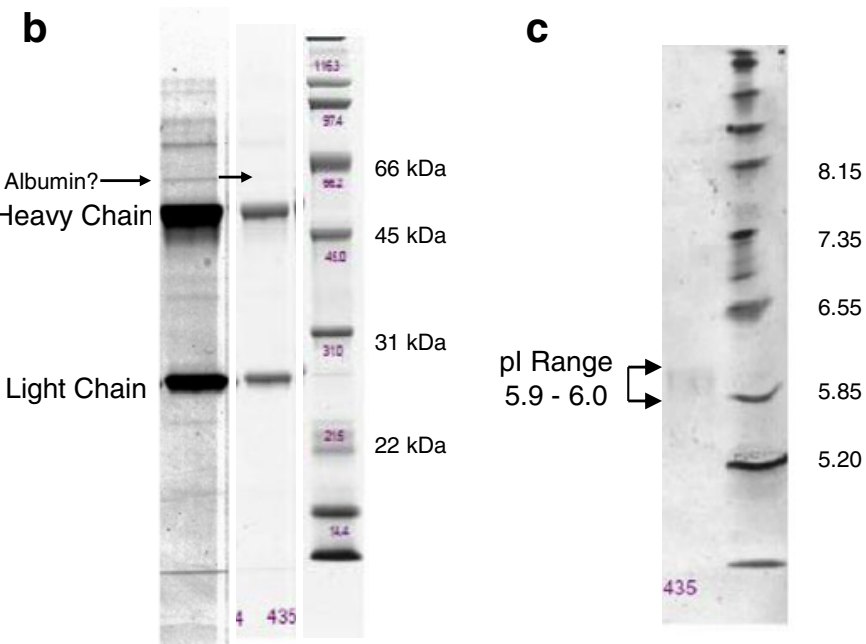

the image contrast to highlight a faint band $(<1 \%)$ that has a similar molecular weight as the albumin standard $(66 \mathrm{kDa})$. The second strip utilized the auto-scale feature available with Quantity One software (Bio-Rad). A $1 \%$ band is noted at approximately $76 \mathrm{kDa}$, and a $3 \%$ band is also seen at approximately $47 \mathrm{kDa}$. $\mathrm{c}$ IEF reveals a tight $\mathrm{p} I$ range of 5.9-6.0. 
Table 4 ISOBM-Abs, biochemical characterization (ABB)

\begin{tabular}{|c|c|c|c|c|c|c|}
\hline \multirow{2}{*}{$\begin{array}{l}\text { ISOBM } \\
\text { Code }\end{array}$} & \multicolumn{3}{|c|}{ GPC-HPLC TOSOH G3000 SWxl column ${ }^{a}$} & \multirow{2}{*}{$\begin{array}{l}\text { SDS-PAGE }{ }^{\mathrm{b}} \\
\% \text { Purity }\end{array}$} & \multirow{2}{*}{$\begin{array}{l}\text { Isotype }^{\mathrm{b}} \\
\text { Heavy/light chain } \\
\text { determination }\end{array}$} & \multirow{2}{*}{$\begin{array}{l}\text { Phastsystem } I F^{b} \\
\mathrm{p} I \text { range }\end{array}$} \\
\hline & $\%$ Purity & $\%$ Aggregation & $\%$ Low $\mathrm{MW}^{\mathrm{c}}$ & & & \\
\hline 382 & 95 & 5 & $<1$ & $99^{\mathrm{d}}$ & IgG1, kappa & $5.8-6.2$ \\
\hline 383 & 98 & $\mathrm{ND}^{\mathrm{e}}$ & 1 & 100 & IgG1, kappa & $6.2-6.8$ \\
\hline 384 & 97 & 2 & $<1$ & 95 & $\mathrm{NT}^{\mathrm{f}}$ & $5.1-5.3$ \\
\hline 385 & 97 & 2 & 1 & $100^{\mathrm{g}}$ & IgG1, kappa & $6.9-7.7$ \\
\hline 386 & 89 & 10 & $<1$ & 96 & NT & $6.7-7.2$ \\
\hline 387 & 98 & 1 & $<1$ & 100 & NT & $6.0-6.4$ \\
\hline 388 & 97 & 2 & $<1$ & $99^{\mathrm{d}}$ & IgG1, kappa & $6.3-7.2$ \\
\hline 389 & 98 & 1 & $<1$ & 99 & NT & $5.9-6.2$ \\
\hline 390 & 98 & 1 & $<1$ & 98 & NT & $6.8-7.6$ \\
\hline 391 & 90 & 1 & $9^{\mathrm{h}}$ & 100 & NT & $6.4-7.4$ \\
\hline 392 & 92 & 7 & $<1$ & 94 & NT & $5.5-5.9$ \\
\hline 393 & 83 & 5 & $12^{\mathrm{i}}$ & 97 & NT & $5.6-6.0$ \\
\hline 394 & 88 & $<1$ & $11^{\mathrm{h}}$ & 100 & NT & $6.7-7.3$ \\
\hline 395 & 97 & 3 & $<1$ & 100 & NT & $6.9-7.5$ \\
\hline 396 & 98 & 2 & $<1$ & 99 & NT & $6.2-6.5$ \\
\hline 397 & 96 & 3 & $<1$ & 99 & NT & Indistinct $^{\mathrm{j}}$ \\
\hline 398 & 97 & 2 & $<1$ & 99 & NT & $6.2-6.6$ \\
\hline 399 & 88 & 11 & $<1^{\mathrm{k}}$ & 99 & NT & $6.4-6.7$ \\
\hline 400 & 96 & 2 & 2 & $96^{\mathrm{d}}$ & IgG1, kappa & $6.1-6.6$ \\
\hline 401 & 98 & 2 & $<1$ & 98 & NT & $6.6-7.3$ \\
\hline 402 & 97 & 1 & 1 & 100 & NT & $6.5-7.2$ \\
\hline 403 & 97 & 2 & $<1$ & 100 & NT & $6.0-6.3$ \\
\hline 404 & 98 & 2 & $<1^{\mathrm{k}}$ & 99 & NT & $6.2-6.8$ \\
\hline 405 & 94 & 5 & $<1^{\mathrm{k}}$ & 99 & IgG1, 2a, 2b, kappa ${ }^{1}$ & $5.5-5.8,6.1-6.6^{\mathrm{m}}$ \\
\hline 406 & 71 & ND & $29^{\mathrm{h}}$ & $100^{\mathrm{d}}$ & IgG1, kappa & $5.0-5.3$ \\
\hline 407 & 91 & 8 & $1^{\mathrm{k}}$ & 99 & NT & $6.2-6.6$ \\
\hline 408 & 89 & 1 & $10^{\mathrm{h}}$ & 100 & NT & $6.1-6.4$ \\
\hline 409 & 64 & ND & $36^{\mathrm{h}}$ & 100 & NT & $6.1-6.4$ \\
\hline 410 & 99 & 1 & $<1$ & 99 & NT & $6.8-7.3$ \\
\hline 411 & 94 & ND & $6^{\mathrm{n}}$ & $96,2^{\circ}$ & NT & $6.0-6.3$ \\
\hline 412 & 95 & 1 & $3^{h, p}$ & 94 & NT & $5.4-5.7$ \\
\hline 413 & 90 & 7 & $2^{\mathrm{h}}$ & 99 & NT & $6.5-7.2$ \\
\hline 414 & 86 & 5 & $10^{\mathrm{h}}$ & 96 & NT & $6.1-6.4$ \\
\hline 415 & 98 & $<1$ & $1^{\mathrm{h}}$ & 100 & NT & $6.0-6.3$ \\
\hline 416 & 74 & $<1$ & $26^{\mathrm{h}}$ & 99 & NT & $5.8-6.2$ \\
\hline 417 & 97 & 1 & $2^{\mathrm{n}}$ & $99,1^{\text {o }}$ & NT & $6.3-6.6$ \\
\hline 418 & 99 & $<1$ & $<1$ & 98 & NT & Indistinct $^{\mathrm{j}}$ \\
\hline 419 & 86 & 3 & $10^{\mathrm{h}}$ & 96 & NT & $5.6-6.0$ \\
\hline 420 & 99 & $<1$ & $<1$ & 100 & NT & $6.6-7.5$ \\
\hline 421 & 97 & 2 & $<1$ & 100 & NT & $6.1-6.6$ \\
\hline 422 & 83 & 1 & $16^{\mathrm{h}}$ & 100 & NT & $5.6-6.0$ \\
\hline 423 & 96 & 2 & $1^{\mathrm{h}}$ & 99 & NT & $6.1-6.5$ \\
\hline 424 & 98 & $<1$ & $<1$ & 99 & NT & $6.2-6.8$ \\
\hline 425 & 98 & $<1$ & 1 & 100 & NT & $6.0-6.7$ \\
\hline 426 & 98 & 1 & $1^{\mathrm{h}}$ & $100^{\mathrm{g}}$ & IgG1, kappa & $6.1-6.4$ \\
\hline 427 & 97 & 2 & $<1^{\mathrm{h}}$ & 99 & NT & $6.0-6.5$ \\
\hline $428^{\mathrm{q}}$ & 81 & 11 & $8^{\mathrm{n}}$ & $98,2^{\circ}$ & NT & $6.0-6.1$ \\
\hline $429^{\mathrm{q}}$ & 92 & 4 & 3 & 100 & NT & $5.9-6.1$ \\
\hline $430^{\mathrm{q}}$ & 97 & 1 & 2 & 100 & NT & $6.0-6.2$ \\
\hline $431^{\mathrm{q}, \mathrm{r}}$ & 89 & ND & ND & 100 & NT & ND \\
\hline
\end{tabular}


Table 4 (continued)

\begin{tabular}{|c|c|c|c|c|c|c|}
\hline \multirow{2}{*}{$\begin{array}{l}\text { ISOBM } \\
\text { Code }\end{array}$} & \multicolumn{3}{|c|}{ GPC-HPLC TOSOH G3000 SWx1 column ${ }^{a}$} & \multirow{2}{*}{$\begin{array}{l}\text { SDS-PAGE } \\
\% \text { Purity }\end{array}$} & \multirow{2}{*}{$\begin{array}{l}\text { Isotype }^{\mathrm{b}} \\
\text { Heavy/light chain } \\
\text { determination }\end{array}$} & \multirow{2}{*}{$\begin{array}{l}\text { Phastsystem } I E F^{\mathrm{b}} \\
\mathrm{p} I \text { range }\end{array}$} \\
\hline & $\%$ Purity & $\%$ Aggregation & $\%$ Low $\mathrm{MW}^{\mathrm{c}}$ & & & \\
\hline 432 & 95 & 4 & 1 & 99 & NT & $6.5-7.0$ \\
\hline 433 & 97 & 2 & $<1$ & 99 & NT & $5.8-6.2$ \\
\hline 434 & 88 & 4 & $7^{\mathrm{n}}$ & $91,2^{\circ}$ & NT & $6.1-6.3$ \\
\hline 435 & 91 & 7 & $2^{\mathrm{n}}$ & $96,1^{\circ}$ & NT & $5.9-6.0$ \\
\hline 436 & 86 & 13 & $1^{\mathrm{n}}$ & $86^{\mathrm{d}, \mathrm{g}}, 1^{\mathrm{o}}$ & IgG1, lambda and kappa ${ }^{\mathrm{s}}$ & $5.7-6.1$ \\
\hline 437 & 88 & 10 & $<1$ & 96 & NT & $6.0-6.3$ \\
\hline 438 & 87 & 11 & $1^{\mathrm{n}}$ & $96,1^{\circ}$ & NT & $5.5-5.7$ \\
\hline 439 & 93 & 5 & $1^{\mathrm{n}}$ & $95,1^{\mathrm{o}}$ & NT & $6.3-6.9$ \\
\hline 440 & 93 & 2 & $5^{\mathrm{n}}$ & $91^{\mathrm{d}}, 2^{\mathrm{o}}$ & IgG1, kappa & $5.9-6.0$ \\
\hline 441 & 83 & 12 & $5^{\mathrm{n}}$ & $94,2^{\circ}$ & NT & $6.2-6.5$ \\
\hline $442^{\mathrm{q}}$ & 57 & 35 & $8^{\mathrm{i}, \mathrm{n}}$ & $85^{\mathrm{d}}, 1^{\mathrm{o}}$ & IgG1, kappa & $5.4-5.7$ \\
\hline 443 & 90 & 9 & 1 & 99 & NT & $6.3-6.6$ \\
\hline 444 & 93 & 4 & $3^{\mathrm{n}}$ & $95,1^{\circ}$ & NT & $6.0-6.3$ \\
\hline 445 & 72 & 25 & $3^{\mathrm{n}}$ & $84,3^{\circ}$ & NT & $5.3-5.5$ \\
\hline 446 & 95 & 3 & $2^{\mathrm{n}}$ & 97 & NT & $6.1-6.4$ \\
\hline 447 & 97 & 2 & $<1$ & 98 & NT & $6.3-6.6$ \\
\hline 448 & 92 & 3 & $5^{\mathrm{n}}$ & $87^{\mathrm{g}}, 3^{\mathrm{o}}$ & IgG2a, kappa & $5.8-6.9$ \\
\hline 449 & 87 & 12 & $<1$ & 95 & NT & $6.1-6.5$ \\
\hline 450 & 89 & 3 & $7^{\mathrm{i}, \mathrm{n}}$ & $90^{\mathrm{d}}$ & IgG1, kappa & $6.0-6.7$ \\
\hline
\end{tabular}

${ }^{\text {a }}$ GPC-HPLC samples were run in triplicate. Mean values are $\pm 1.9 \%$, which is established from the largest standard deviation (SD) observed. Triplicate injections of sample 442 had the largest SD of 1.91

${ }^{\mathrm{b}}$ Single lanes or strips were run for these tests, to preserve sample for additional testing.

${ }^{\mathrm{c}}$ All the samples have peaks with the same retention time as sodium azide. The presence of sodium azide could not be confirmed due to lack of sample volume to perform additional testing.

${ }^{\mathrm{d}}$ Double light chains. Possible causes for double chains include but are not limited to; glycosylation differences, amino acid residue differences or more than one antibody present in the sample

${ }^{\mathrm{e}}$ Not Detected

${ }^{\mathrm{f}}$ Not Tested, only samples exhibiting double heavy or light chains by SDS-PAGE or multiple clusters of bands by IEF underwent isotype analysis.

${ }^{g}$ Double heavy chains.

${ }^{\mathrm{h}}$ These samples have peaks that could represent high levels of residual citrate in these samples. Residual testing would need to be performed to confirm this. Testing was not performed due to lack of sample volume. High levels of citrate can react with iron that may be present in HPLC equipment forming iron-citrate complexes. This phenomenon has been observed in other samples containing high citrate levels at retention times of approximately 11.3 minutes using a G3000SWxl Column and our Waters HPLC system.

${ }^{\mathrm{i}}$ A tailing shoulder is present behind the main antibody peak.

${ }^{\mathrm{j}}$ The sample only produced a smear, possibly due to a high salt concentration.

${ }^{\mathrm{k}}$ Retention times of 9.2 to 9.6 minutes correspond to a molecular weight of $20-30 \mathrm{kDa}$ and could represent free light chain material. The molecular weight determination was obtained by plotting the logarithm of the GFS molecular weights versus their retention times.

${ }^{1}$ Two types of heavy chain isotypes indicate this sample is probably not derived from a single clone.

${ }^{\mathrm{m}}$ Two $\mathrm{pI}$ ranges indicate this sample may not be derived from a single clone.

${ }^{\mathrm{n}}$ These samples have peaks that have a similar retention time as albumin. The presence of albumin could not be confirmed due to lack of sample volume to perform additional testing.

${ }^{\circ}$ A band was observed near the albumin standard.

${ }^{\mathrm{p}}$ These samples have peaks that have a similar retention time as DTT. The presence of DTT could not be confirmed due to lack of sample volume to perform additional testing.

${ }^{\mathrm{q}}$ Sheep Antibody

${ }^{\mathrm{r}}$ The label concentration may be incorrect. The observed signals were not consistent with the label concentration.

${ }^{\mathrm{s}}$ Two types of light chain isotypes indicate this sample is probably not derived from a single clone.

GFS Standards: thyroglobulin MW 670,000, RT 6.0-6.1; gamma-globulin MW 158,000, RT 7.9-8.0; ovalbumin MW 44,000, RT 9.2-9.3, myoglobin MW 17,000, RT 10.3-10.4, vitamin B12 MW 1,350, RT 11.9-12.0 
glycosylation and ISOBM-426 complex heavy chains and ISOBM-450 complex light chains (Online Resource 18).

\section{Ab affinities, specificities, and epitope localizations}

Ab specificities (NRH) Based on the results of DB-RIAs with ${ }^{125}$ I-labeled hCG, hCG-variants, and hLH tracers, the 69 ISOBM-Abs were categorized according to their main specificities ( $\alpha-, \beta-$, and c-mAbs) (Fig. 4): Antibodies either recognized (a) assembled and/or free hCG $\alpha$ (hCG $\alpha$-mAbs, $n=8$; $\alpha$ epitopes were not determined) or (b) assembled and/or free hCG $\beta$ or hCG $\beta$ metabolites such as hCG $\beta$ cf (hCG $\beta$-mAbs, $n=48$; epitopes $\beta_{1}-\beta_{13}$ ), or (c) exclusively the intact \pm nicked hCG $\alpha \beta$ heterodimer, but not the free subunits or metabolic variants thereof (c-mAbs, $n=13$; epitopes $\mathrm{c}_{1}-\mathrm{c}_{4}$ ).

Comparing specificity profiles of ISOBM-Abs to those of reference $m A b s$ permitted preliminary epitope assignment. To discern mAbs against epitopes $\beta_{1}-\beta_{5}$, hLH crossreactivity was determined by titration RIAs with ${ }^{125} \mathrm{I}-\mathrm{hLH}$ (Fig. 4). Recognition of hCG $\beta C T P$ was investigated by competitive RIA using synthetic peptides derived from hCG $\beta$ CTP (Fig. 4a; Online Resource 19). No mAbs against epitope $\beta_{14}$ (hCG $\beta$ specific) were identified in this ISOBM panel (Fig. 4a).

Ab affinities and specificities as determined by FRET (ABB) The ISOBM-Abs were grouped according to their specificity profiles based on affinity for hCG, hCG $\beta$, hCG $\beta c f$, and hLH (Fig. 5) determined by FRET. Affinities for the major hCG variants and $\mathrm{hLH}$, reported as dissociation constants $\left(K_{\mathrm{d}}\right)$, ranged from subpicomolar values $(0.3 \mathrm{pmol} / \mathrm{L}$ for $\mathrm{hCG} \beta$ of ISOBM-429) to $\geq 50 \mathrm{nmol} / \mathrm{L}$. The latter value indicated that binding was very weak or not detectable.

Only nine Abs (ISOBM-387, ISOBM-399, ISOBM-401, ISOBM-414, ISOBM-416, ISOBM-427, ISOBM-428, ISO BM-429, and ISOBM-444) expressed high affinities $\left(K_{\mathrm{d}}\right.$, $\leq 50 \mathrm{pmol} / \mathrm{L}$ ) for any of the four antigens tested (hCG, hCG $\beta$, $\mathrm{hCG} \beta \mathrm{cf}$, and $\mathrm{hLH})$. It is striking that six of these mAbs recognize the major antigenic domain on the tips of $h C G \beta$ loops $1+3$. An exception was the hCG $\beta$ cf-specific $\mathrm{mAb}$ ISO BM-444 (reference mAb INN-hCG-106), the epitope of which $\left(\beta_{11}\right)$ does not overlap with epitopes $\beta_{2}-\beta_{5}$ on hCG $\beta$ loops $1+3$ nor with the cystine knot-associated epitopes $\beta_{1}$ and $\beta_{7}$. Thus, this epitope is remote from either cluster. This is an interesting $\mathrm{mAb}$ for highly sensitive and specific measurement of hCG $\beta \mathrm{cf}$ in particular in combination with $\beta_{2^{-}}$ mAbs $[9,36]$.

Another interesting observation is that all three sheep mAbs, ISOBM-428, ISOBM-429 and ISOBM-430, were in the high affinity group. ISOBM-430 was not tested by the FRET technology but by titration RIA. All four sheep Abs (three $\mathrm{mAbs}$ and polyclonal ISOBM-431) were directed against hCG $\beta$ loops $1+3$ epitope $\beta_{5}$ that is shared by hLH
Fig. 4 Specificity profiles of the ISOMB-Abs of the Second TD-7 WS recognizing $\mathrm{hCG}$ and $\mathrm{hCG} \beta$ variants (a), hCG-only and $\mathrm{hCG} \alpha$, respectively (b) were determined by binding of iodinated tracers to excess of $\mathrm{Ab}$ (DB-RIA) (NRH). ISOBM-mAbs were classified according to their main specificities and their epitopes recognized on the basis of crossreactivity patterns with hCG, hCG-variants, and hLH: (1) $\beta$-mAbs corresponding to epitopes $\beta_{1}-\beta_{13}$, (2) c-mAbs recognizing epitopes $\mathrm{c}_{1}-\mathrm{c}_{4}$ on holo-hCG only, and (3) $\alpha$-mAbs. a MAbs directed against epitopes $\beta_{1}-\beta_{5}$ are pan-hCG reagents recognizing hCG and hCG $\beta$ variants but differ in their cross-reactivity with hLH: $\beta_{1}$ mAbs are highly specific for hCG and show no hLH cross-reactivity $(<0.1 \%), \beta_{2}$ and $\beta_{4}$ show very low hLH reactivity $(<1 \%)$, whereas $\beta_{3}$ and $\beta_{5}$ strongly cross-react $(>>1 \%)$. Epitopes $\beta_{6}$ and $\beta_{7}$ are specific for uncombined hCG $\beta, h C G \beta n$, and hCG $\beta$ cf. MAbs against epitope $\beta_{8}$ at the very carboxyl-terminal end of hCG $\beta C T P$ do not cross-react with hCG $\beta c f$ and $h L H$ but recognize all other hCG variants except for those lacking the CTP. These mAbs constantly show a low bindable fraction of the tracers as only approximately $50 \%$ of the tracers can be bound specifically. This is in contrast to the $\beta_{1}-\beta_{5} \mathrm{mAbs}$. ISOBM-418 seems to be directed against epitope $\beta_{9}$ as already typed previously in the First WS (ISOBM-280, [1]. Epitopes $\beta_{10}-\beta_{13}$ are specific for $\mathrm{hCG} \beta \mathrm{cf}$ as no other $\mathrm{hCG}$ variants or $\mathrm{hLH}$ are recognized by the respective mAbs. b c-mAbs directed against epitopes determined by the quaternary structure of hCG either do not $\left(\mathrm{c}_{1}\right.$ and $\left.\mathrm{c}_{2}\right)$ or do recognize $\mathrm{hCGn}$ $\left(c_{3}\right.$ and $\left.c_{4}\right)$ [56]. The apparent hCGn cross-reactivity of $c_{1}$ and $c_{2} m A b s$ is due to a cross-contamination of this preparation with non-nicked hCG (approximately $20 \%$ ) [1]. The presence of non-nicked hCG and recognition by the ISOBM-mAbs of the two-nicked forms in hCGn were investigated in detail by LC-MS/MS (see accompanying publication by $\mathrm{H}$. Lund). Epitope $c_{3}$ (ISOBM-446 $=\mathrm{INN}-\mathrm{hCG}-45$, reference $\mathrm{mAb}$ ) is highly specific for $h C G+h C G n$. ISOBM-mAb 433 that has the same specificity pattern might be directed against a fifth sterically independent c-epitope as shown by sandwich assay. The exact molecular localization of epitope $\mathrm{c}_{4}$ on hCG is not known, but it is remote from the other c-epitopes. In the First ISOBM TD-7 WS, ISOBM-424 has been characterized (ISOBM-279) and classified as $c_{4}$ specific [1]. The $\alpha$-mAbs have not been investigated in detail as to their epitope recognition. As they readily recognized iodinated tracers (in contrast to $\alpha_{3}$ - and $\alpha_{5}$-mAbs), they should be directed against the epitope cluster $\alpha_{1} / \alpha_{2} / \alpha_{4}$ with the exception of ISOBM-404 that is free hCG $\alpha$ specific and therefore presumably recognizing the subunit assembly region of hCG $\alpha$ (aa hCG $\alpha 33-42$ ). Minor apparent cross-reactivity with hCGn is owed to a cross-contamination of $\mathrm{hCG} \alpha$ in that preparation. hLH crossreactivity of ISOBM-404 might be due to dissociation of highly purified $\mathrm{hLH}$ that is observed during testing (PB, personal observation). DB-RIA with ${ }^{125}$ I-tracers: results are expressed as maximum specific binding in percent of the "bindable fraction" of added tracer (NRH) [26]. Italics RIA titration experiments (NRH): Results are expressed as percent hLH crossreactivities compared to hCG; asterisk ${ }^{125} \mathrm{I}$-tracers; gray background significant cross-reactions. Superscripted a Apparent cross-reactivities with hCGn of ISOBM-447-438 are caused by an approximate $20 \%$ crosscontamination of intact hCG (see accompanying publication by $\mathrm{H}$. Lund) and superscripted $b$ of ISOBM-383-404 due to a suchlike with hCG $\alpha$ that is contained in hCG $\beta \mathrm{n}$; superscripted $c$ ISOBM-404: apparent crossreactivity is probably caused by slight dissociation of $\alpha$-subunit in hLH. Section symbol Competitive RIA with hCG $\beta 109-145$ vs. hCG $\beta *$, percent cross-reactivity. Double section symbol Competitive RIA with hCG $\beta 135$ 145 vs. hCG $\beta^{*}$, percent cross-reactivity

and, therefore, in principle, do not seem suitable for hCG measurement. Nevertheless, ISOBM-429 seems to have tolerably low cross-reactivity with hLH (Figs. $4 \mathrm{a}$ and 5 and Online Resource 20), but its suitability for use in $\mathrm{hCG}+\mathrm{hCG} \beta$ variant measurement might still be hampered by preferential recognition of hCG $\beta$. 


\begin{tabular}{|c|c|c|c|c|c|c|c|c|c|}
\hline Code & hCG* & hCGn* & hCG $\beta^{*}$ & hCG $\beta n^{*}$ & hCG $\beta$ cf* & $\mathrm{hLH}^{*}$ & $\beta 109^{\S}$ & $\beta 135^{\S \S}$ & Epitope \\
\hline 403 & 72 & 66 & 96 & 81 & 88 & $<0.1$ & \multirow{35}{*}{ n.d. } & \multirow{35}{*}{ n.d. } & \\
\hline 435 & 61 & 57 & 89 & 74 & 86 & $<0.1$ & & & $\beta_{1}$ \\
\hline 382 & 91 & 79 & 86 & 81 & 86 & 0.5 & & & \multirow{10}{*}{$\beta_{2}$} \\
\hline 388 & 86 & 96 & 93 & 81 & 81 & 0.1 & & & \\
\hline 390 & 89 & 98 & 96 & 83 & 86 & 0.1 & & & \\
\hline 402 & 95 & 101 & 100 & 88 & 89 & 0.3 & & & \\
\hline 408 & 82 & 74 & 101 & 60 & 69 & $<0.1$ & & & \\
\hline 416 & 82 & 92 & 89 & 79 & 79 & 0.2 & & & \\
\hline 417 & 75 & 80 & 76 & 79 & 71 & 0.1 & & & \\
\hline 426 & 91 & 80 & 85 & 83 & 85 & 0.1 & & & \\
\hline 427 & 90 & 80 & 85 & 90 & 84 & $<0.1$ & & & \\
\hline 449 & 94 & 86 & 98 & 93 & 92 & 0.1 & & & \\
\hline 396 & 73 & 70 & 54 & 50 & 51 & 126 & & & \multirow{8}{*}{$\beta_{3}$} \\
\hline 399 & 92 & 93 & 99 & 83 & 88 & 18 & & & \\
\hline 400 & 51 & 40 & 68 & 64 & 71 & 311 & & & \\
\hline 401 & 65 & 53 & 85 & 74 & 79 & 175 & & & \\
\hline 405 & 92 & 100 & 100 & 88 & 87 & 45 & & & \\
\hline 423 & 90 & 79 & 75 & 71 & 71 & 45 & & & \\
\hline 434 & 32 & 26 & 55 & 38 & 68 & 264 & & & \\
\hline 441 & 23 & 17 & 60 & 43 & 61 & 127 & & & \\
\hline 419 & 90 & 50 & 40 & 36 & 47 & 0.8 & & & \multirow{2}{*}{$\beta_{4}$} \\
\hline 445 & 90 & 82 & 53 & 93 & 92 & 0.8 & & & \\
\hline 428 & 22 & 21 & 25 & 29 & 43 & 34 & & & \multirow{5}{*}{$\beta_{s}$} \\
\hline 429 & 21 & 21 & 24 & 26 & 42 & 3 & & & \\
\hline 430 & 70 & 74 & 79 & 100 & 98 & 20 & & & \\
\hline 431 & 68 & 39 & 79 & 98 & 100 & 29 & & & \\
\hline 442 & 95 & 87 & 98 & 90 & 91 & 100 & & & \\
\hline 410 & 1 & 1 & 99 & 86 & 85 & 1 & & & \multirow{2}{*}{$\beta_{6}$} \\
\hline 437 & 1 & 1 & 33 & 26 & 30 & 0 & & & \\
\hline 386 & 13 & 6 & 89 & 48 & 30 & 0 & & & \multirow{6}{*}{$\beta_{7}$} \\
\hline 397 & 1 & 2 & 49 & 45 & 35 & 0 & & & \\
\hline 407 & 0 & 1 & 88 & 74 & 4 & 0 & & & \\
\hline 409 & 0 & 1 & 85 & 81 & 78 & 0 & & & \\
\hline 415 & 0 & 2 & 78 & 86 & 55 & 1 & & & \\
\hline 439 & 4 & 3 & 64 & 57 & 44 & 0 & & & \\
\hline 406 & 91 & 83 & 64 & 43 & 0 & 0 & $<0.1$ & $<0.001$ & $\beta$ \\
\hline 450 & 7 & 4 & 10 & 7 & 0 & 0 & n.d. & 105 & \multirow{4}{*}{$\begin{array}{c}t_{1} \\
\beta_{8} \\
t_{2}\end{array}$} \\
\hline 395 & 52 & 37 & 55 & 48 & 0 & 0 & 44 & 0.1 & \\
\hline 413 & 36 & 33 & 51 & 45 & 0 & 0 & 42 & 0.1 & \\
\hline 420 & 38 & 31 & 53 & 45 & 0 & 0 & 52 & 0.1 & \\
\hline 394 & 92 & 87 & 90 & 83 & 0 & 0 & 7 & $<0.001$ & \multirow{2}{*}{$\beta_{9}$} \\
\hline 418 & 0 & 0 & 13 & 7 & 0 & 0 & $<0.1$ & n.d. & \\
\hline 392 & 3 & 2 & 20 & 5 & 0 & 1 & $<0.1$ & $<0.001$ & $\beta$ \\
\hline 384 & 0 & 0 & 1 & 0 & 78 & 0 & \multirow{5}{*}{ n.d. } & \multirow{5}{*}{ n.d. } & \multirow{5}{*}{$\beta \mathbf{c f}$} \\
\hline 393 & 0 & 0 & 1 & 0 & 50 & 0 & & & \\
\hline 448 & 0 & 0 & 1 & 0 & 48 & 0 & & & \\
\hline 444 & 0 & 0 & 1 & 0 & 76 & 0 & & & \\
\hline 443 & 0 & 0 & 1 & 0 & 57 & 0 & & & \\
\hline
\end{tabular}


b

\begin{tabular}{|c|c|c|c|c|c|c|c|c|}
\hline Code & hCG $^{*}$ & a) CGn* $^{*}$ & hCG $\beta^{*}$ & $\left.{ }^{b}\right)$ hCG $\beta n^{*}$ & hCG $\beta c f^{*}$ & hLH $^{*}$ & $\mathbf{h C G} \alpha^{*}$ & Epitope \\
\hline 414 & 98 & 21 & 1 & 0 & 0 & 100 & \multirow{13}{*}{ n.d. } & \multirow[b]{2}{*}{$c_{1}$} \\
\hline 447 & 90 & 14 & 1 & 0 & 0 & 1.3 & & \\
\hline 389 & 95 & 14 & 5 & 0 & 0 & $<0.1$ & & C \\
\hline 411 & 92 & 16 & 1 & 0 & 0 & $<0.1$ & & \multirow{4}{*}{$c_{2}$} \\
\hline 422 & 93 & 14 & 1 & 0 & 0 & $<0.1$ & & \\
\hline 425 & 77 & 9 & 1 & 0 & 0 & $<0.1$ & & \\
\hline 387 & 90 & 14 & 1 & 0 & 0 & 0.1 & & \\
\hline 436 & 50 & 8 & 1 & 0 & 0 & 7 & & \multirow[b]{2}{*}{$c_{2}$} \\
\hline 438 & 100 & 22 & 1 & 0 & 0 & 157 & & \\
\hline 446 & 59 & 50 & 0 & 0 & 0 & $<0.1$ & & $c_{3}$ \\
\hline 424 & 89 & 80 & 5 & 5 & 0 & $<0.1$ & & \multirow{2}{*}{$C_{4}$} \\
\hline 440 & 84 & 64 & 1 & 0 & 0 & 48 & & \\
\hline 433 & 97 & 80 & 1 & 0 & 0 & $<0.1$ & & C \\
\hline 383 & 76 & 87 & 1 & 14 & 0 & 100 & 100 & \multirow{7}{*}{$\alpha$} \\
\hline 385 & 96 & 76 & 1 & 14 & 0 & 97 & 92 & \\
\hline 391 & 50 & 36 & 0 & 5 & 0 & 62 & 61 & \\
\hline 398 & 24 & 22 & 4 & 10 & 9 & 32 & 51 & \\
\hline 412 & 46 & 31 & 0 & 5 & 0 & 54 & 62 & \\
\hline 421 & 50 & 34 & 0 & 5 & 0 & 63 & 63 & \\
\hline 432 & 43 & 26 & 0 & 5 & 0 & 18 & 17 & \\
\hline 404 & 4 & 11 & 0 & 10 & 0 & ${ }^{c)} 22$ & 96 & $\alpha_{6} ?$ \\
\hline
\end{tabular}

Fig. 4 (continued)

Most Abs, including all directed against the cystine knotassociated epitopes $\beta_{1}$ and $\beta_{7}$, the hCG $\beta$ CTP epitope $\beta_{8}$ types 1 and 2 , showed moderate affinities $(50 \mathrm{pmol} / \mathrm{L}-5 \mathrm{nmol} / \mathrm{L})$ against their primary target hCG variant. Low affinities could be observed for three reasons: (1) the primary antigenic target hCG variant of the mAb in question was not among the antigens tested, as is the case of mAbs against uncombined hCG $\alpha$ (ISOBM-404), or (2) genuine low affinity to the primary target antigens, e.g., ISOBM-418/280 (hCG $\beta$ CTP epitope $\beta_{9}$, aa $h C G \beta 113-116)$ and ISOBM-443 and 448 against $h C G \beta c f$, and (3) FRET labeling affected binding of Abs (ISOBM-445 to hCG $3 \mathrm{cf}$; ISOBM-399, ISOBM-436, ISOBM-412, and ISO BM-421 to hLH) (Fig. 5). This is also the case with ${ }^{125} \mathrm{I}-$ labeling of epitopes $\alpha_{3}$ and $\alpha_{5}$ [37].

Ab affinities and specificities as determined by BIAcore ${ }^{\circledR}$ (NHD) The specificity patterns of the ISOBM-Abs were determined based on their affinity for $\mathrm{hCG}, \mathrm{hCG} \beta$, and hCG $\beta$ cf in BIAcore ${ }^{\circledR}$. The affinities (dissociation constants; $\left.K_{\mathrm{d}}\right)$ ranged from picomolar values $(<10 \mathrm{pM}$ for hCG of ISOBM-399) to $>10 \mathrm{nM}$. An affinity of $<100 \mathrm{nM}$ was observed for 43 of the Abs for either a single or a combination of the three antigens tested (hCG, hCG $\beta$, and hCG $\beta \mathrm{cf}$ ). Five of these Abs, ISOBM-427 (epitope $\beta_{2}$ ), ISOBM-399, ISOBM-423, ISOBM-441 (all three epitope $\beta_{3}$ ), and
ISOBM-428 (epitope $\beta_{5}$ ) had affinities of $<10 \mathrm{pM}$ for the antigen. It is striking that all of these recognize the tops of hCG $\beta$ loops $1+3$; thus, all epitopes were located within the same antigenic domain. Assignment of epitopes to the ISOBM-Abs was achieved by comparing their specificity profiles to those of reference mAbs (Online Resource 20).

The affinity of many of the ISOBM-Abs appeared to be higher than determined by FRET analysis. This could perhaps be a consequence of having the antigen in a bound form on the BIAcore ${ }^{\circledR}$ chip rather than in a fluid state. The affinity for this immobilized form of antigen may result in an overestimate of affinity.

Ab specificities as determined by CLA (NHD) In the CLA approach, ISOBM-Abs were titrated against ${ }^{125} \mathrm{I}-\mathrm{hCG}$ and in parallel competed with a fixed amount $(0.5 \mathrm{pmol} / \mathrm{mL})$ of hCG, hCG-variants, and hLH, respectively. A shift of the $\mathrm{Ab}$ dilution curves to a lower titre indicated cross-reactivity of this competitor with the Ab. Based on the CLA results, 34 ISOBM-Abs, either recognized (a) assembled and/or free

Fig. 5 Affinity and specificity of the ISOBM-Abs as determined by FRET (ABB). Preliminary assignment of epitopes was done by comparing the specificity profiles of the ISOBM-Abs to those of reference mAbs. Specificities based on affinity of mAbs against hCG $\alpha$ could not be determined with hCG, hCG $\beta$, and hCG $\beta \mathrm{cf}$ 


\begin{tabular}{|c|c|c|c|c|c|c|c|}
\hline $\begin{array}{c}\text { ISOBMii } \\
\text { Ab Codes }\end{array}$ & $\begin{array}{c}\text { hCG } \\
\text { affinity } \\
{[\mathrm{nM}]}\end{array}$ & $\begin{array}{c}\text { hCG } \beta \\
\text { affinity } \\
{[n M]}\end{array}$ & $\begin{array}{c}\text { hCG } \beta \text { cf } \\
\text { affinity } \\
{[\mathrm{nM}]}\end{array}$ & LH [nM] & $\begin{array}{l}\text { Specificity Based on } \\
\text { Affinity: hCG, } \beta, \beta \text { cf }\end{array}$ & $\begin{array}{l}\text { Specificity } \\
\text { Based on } \\
\text { Affinity: } \mathrm{hLH}\end{array}$ & Epitope \\
\hline 403 & 1.17 & 0.65 & 0.29 & $>50$ & \multirow{27}{*}{$\begin{array}{c}\mathrm{hCG}+\mathrm{hCG} \beta \\
\mathrm{hCG} \beta \mathrm{cf}\end{array}$} & \multirow[b]{2}{*}{-} & \multirow{2}{*}{$\beta_{1}$} \\
\hline $435^{*}$ & 1.15 & 0.52 & 0.32 & $>50$ & & & \\
\hline 382 & 0.66 & 0.51 & 0.16 & 3.90 & & \multirow{10}{*}{-} & \multirow{10}{*}{$\beta_{2}$} \\
\hline 388 & 0.14 & 0.11 & 0.11 & 24.00 & & & \\
\hline 390 & 0.14 & 0.10 & 0.07 & $>50$ & & & \\
\hline 402 & 0.08 & 0.06 & 0.18 & 16.90 & & & \\
\hline 408 & 0.10 & 0.48 & 0.40 & $>50$ & & & \\
\hline 416 & $?$ & 0.04 & 0.02 & $>50$ & & & \\
\hline 417 & 0.37 & 0.30 & 0.10 & $>50$ & & & \\
\hline 426 & 0.13 & 0.17 & 0.25 & $>50$ & & & \\
\hline 427 & 0.08 & 0.04 & 0.03 & $>50$ & & & \\
\hline $449^{*}$ & 0.34 & 0.15 & 0.15 & 12.30 & & & \\
\hline 396 & 0.20 & 0.94 & 0.90 & 0.17 & & \multirow{8}{*}{$\mathrm{hLH}$} & \multirow{8}{*}{$\beta_{3}$} \\
\hline 399 & 0.13 & 0.03 & 0.02 & $?$ & & & \\
\hline 400 & 1.60 & 0.35 & 0.23 & 0.33 & & & \\
\hline 401 & 0.86 & 0.08 & 0.01 & 0.30 & & & \\
\hline 405 & 0.17 & 0.13 & 0.19 & 0.50 & & & \\
\hline 423 & 0.06 & 0.06 & 0.10 & 0.10 & & & \\
\hline $434^{*}$ & 11.60 & 16.50 & 6.10 & 3.60 & & & \\
\hline $441^{*}$ & 5.40 & 0.75 & 1.20 & 0.70 & & & \\
\hline 419 & 0.34 & 0.35 & 0.23 & $>50$ & & - & \\
\hline $445^{*}$ & 0.78 & 0.76 & $?$ & $>50$ & & - & $\beta_{4}$ \\
\hline 428 sheep & 0.01 & 0.003 & 0.01 & 0.10 & & \multirow{5}{*}{ hLH } & \multirow{5}{*}{$\beta_{5}$} \\
\hline 429 sheep & 0.004 & 0.0003 & 0.03 & 0.40 & & & \\
\hline 430 sheep & n.d. & n.d. & n.d. & n.d. & & & \\
\hline 431 sheep & 0.35 & 0.14 & 0.20 & 0.60 & & & \\
\hline $442^{*}$ & 0.36 & 0.25 & 0.07 & 0.10 & & & \\
\hline 410 & 49.00 & 0.08 & 0.07 & $>50$ & \multirow{8}{*}{ hCG $\beta+$ hCG $\beta c f$} & & \\
\hline $437^{\star}$ & $>50$ & 2.75 & 3.75 & $>50$ & & & $\beta_{6}$ \\
\hline 386 & 6.32 & 0.23 & 0.50 & $>50$ & & & \\
\hline 397 & $>50$ & 4.99 & 8.60 & $>50$ & & & \\
\hline 407 & $>50$ & 0.70 & $>50$ & $>50$ & & - & \\
\hline 409 & $>50$ & 1.32 & 1.55 & $>50$ & & & $\beta_{7}$ \\
\hline 415 & 40.40 & 1.27 & 4.83 & $>50$ & & & \\
\hline $439^{*}$ & $>50$ & 0.54 & 1.92 & $>50$ & & & \\
\hline $450^{*}$ & 0.23 & 2.88 & $>50$ & $>50$ & & & \\
\hline 395 & 0.25 & 1.93 & $>50$ & $>50$ & & & \\
\hline 413 & 0.54 & 1.74 & $>50$ & $>50$ & $\mathrm{hCG}+\mathrm{hCG} \beta$ & - & $P_{8}$ \\
\hline 420 & 0.32 & 1.89 & $>50$ & $>50$ & & & \\
\hline 394 & 0.09 & 0.67 & $>50$ & $>50$ & & & \\
\hline 418 & $>50$ & $>50$ & $>50$ & $>50$ & $?$ & - & $\beta_{9}$ \\
\hline 392 & $>50$ & 12.40 & $>50$ & $>50$ & & & \\
\hline 406 & 0.16 & 0.23 & $>50$ & $>50$ & & & $\beta$ \\
\hline 384 & $>50$ & $>50$ & 4.10 & $>50$ & & & \\
\hline 393 & $>50$ & $>50$ & 4.00 & $>50$ & & & \\
\hline $443^{*}$ & $>50$ & $>50$ & $>50$ & $>50$ & hCG $\beta c f$ only & _- & $\beta c f$ \\
\hline $444^{*}$ & $>50$ & $>50$ & 0.05 & $>50$ & & & \\
\hline $448^{*}$ & $>50$ & $>50$ & $>50$ & $>50$ & & & \\
\hline 414 & 0.01 & $>50$ & $>50$ & 0.04 & & & \\
\hline $447^{*}$ & 0.44 & $>50$ & $>50$ & 3.00 & & $\mathrm{hLH}$ & $c_{1}$ \\
\hline 387 & 0.05 & $>50$ & $>50$ & 1.20 & & $\mathrm{hLH}$ & \\
\hline 411 & 2.45 & $>50$ & $>50$ & $>50$ & & & \\
\hline 422 & 0.06 & $>50$ & $>50$ & 21.80 & & - & \\
\hline 425 & 0.12 & $>50$ & $>50$ & 2.10 & & & $\mathrm{C}_{2}$ \\
\hline $436^{*}$ & 0.35 & $>50$ & $>50$ & $?$ & hCG only & hLH & \\
\hline $438^{*}$ & 0.06 & $>50$ & $>50$ & 0.50 & & & \\
\hline $446^{*}$ & 1.07 & $>50$ & $>50$ & $>50$ & & _- & $\mathrm{C}_{3}$ \\
\hline 424 & 0.29 & $>50$ & $>50$ & $>50$ & & & $c$ \\
\hline $440^{*}$ & 3.55 & $>50$ & $>50$ & 1.00 & & $\mathrm{hL}$ & $\mathrm{C}_{4}$ \\
\hline 389 & 0.19 & 35.70 & $>50$ & $>50$ & & - & \\
\hline 433 & 0.35 & $>50$ & $>50$ & $>50$ & & - & c \\
\hline 383 & 0.30 & $>50$ & $>50$ & 0.24 & & & \\
\hline 385 & 0.07 & $>50$ & $>50$ & 0.12 & & & \\
\hline 391 & 0.05 & $>50$ & $>50$ & 0.09 & & & \\
\hline 398 & 15.00 & 29.00 & $>50$ & 3.80 & & hLH & $\alpha$ \\
\hline 412 & 0.29 & $>50$ & $>50$ & $?$ & $?$ & & \\
\hline 421 & 0.20 & $>50$ & $>50$ & $?$ & & & \\
\hline 432 & 0.34 & $>50$ & $>50$ & 0.60 & & & \\
\hline 404 & $>50$ & $>50$ & $>50$ & 28.00 & & - & $\alpha_{6}$ \\
\hline
\end{tabular}

\begin{tabular}{|l|l|}
\hline${ }^{*}$ reference antibodies & I.C. ... internal control \\
\hline
\end{tabular}

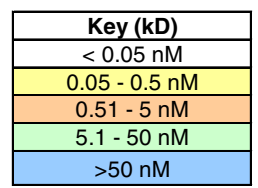


hCG $\beta$ metabolites such as hCG $\beta$ cf (hCG $\beta$-mAbs, $n=24$; epitopes $\beta_{1}-\beta_{9}$ ) or (b) exclusively $\mathrm{hCG} \pm \mathrm{hCG} \beta$, but not the free subunits (c-mAbs, $n=10$; epitopes $\left.\mathrm{c}_{1}-\mathrm{c}_{4}\right)$. Epitope assignment was achieved by comparing profiles of the reference mAbs with ISOBM-Abs (Online Resource 20).

No CLA analysis was possible for 35 ISOBM-Abs, which had very low or no signal, which suggested that the Ab did not recognize ${ }^{125} \mathrm{I}-\mathrm{hCG}$ or could not be competed with the amounts utilized.

Epitope classification by sandwich assays (NRH) IRMAlike sandwich assays were performed to confirm preliminary $\mathrm{Ab}$ epitope classifications by specificity assays and to determine epitope localization by comparison with reference mAbs. Characteristic reaction patterns were observed when solid-phase bound ISOBM-mAbs were tested for their ability to sandwich hCG or hCG $\beta$ with the panel of reference $\mathrm{mAbs}$ directed against epitopes $\beta_{1}-\beta_{9}$ (Fig. 6a) and $c_{1}-c_{4}$ (Fig. 6b). Patterns observed agreed with previously determined epitope locations for the reference mAbs $[28,38]$.

Compatibility of $\mathrm{Ab}$ pairs in sandwich assays indicated that their epitopes were spatially distinct, e.g., epitopes $\beta_{1}$ versus $\beta_{2}-\beta_{6}$ and vice versa (Fig. 6a). Identical or highly similar compatibility patterns of Abs to that of reference or other mAbs indicated recognition of identical or of neighboring epitopes within the same antigenic domain: e.g., the cystine knot-related epitopes $\beta_{1}$ and $\beta_{7}$, or epitopes $\beta_{2}, \beta_{4}$, and $\beta_{5}$ on hCG $\beta$ loops $1+3$. Epitopes within a particular antigenic domain can be easily discerned by cross-reactivity patterns with hCG variants and LH from various species [1]. Thus, although $\beta_{1}$ - and $\beta_{7}$-mAbs show identical compatibility patterns in sandwich assays and are not compatible with each other (Fig. 6a), they recognize different but spatially adjacent cystine knot-related epitopes reflected by differing variant recognition patterns: $\beta_{1}-\mathrm{mAbs}$ recognize a broad spectrum of hCG-variants whereas $\beta_{7}$-mAbs are highly selective for $h C G \beta, h C G \beta n \pm h C G \beta c f$ and do not recognize hCG (Fig. 4).

Antigenic domains and epitope maps of $h C G$ and $h C G \beta$ (INN) Results of the three approaches for epitope typing are summarized in Table 5. In Fig. 7, the ISOBM-mAbs are assigned to the three-dimensional epitope maps of hCG $\beta$ (a) and hCG (b), which were established with the reference mAbs previously [1]. The Abs grouped according to epitope recognition are listed in Table 8 in Appendix.

In the ISOBM panel, 48 out of 69 were $\beta$-Abs. The major antigenic domain on hCG $\beta$ located on the tips of the neighboring $\beta$-sheet loops 1 and +3 encompassing aa hCG $\beta 20-25$ and 68-77 (epitopes $\beta_{2}-\beta_{6}$ ) was recognized by 27 of the $\beta$ Abs. Of these, 12 Abs recognize epitopes $\beta_{2}$ or $\beta_{4}\left(\beta_{2 / 4}\right), 13$ epitopes $\beta_{3}$ or $\beta_{5}\left(\beta_{3 / 5}\right)$, and 2 epitope $\beta_{6}$. Epitopes $\beta_{2}-\beta_{5}$
Fig. 6 Classification and spatial relationship of ISOBM-mAb epitopes. Two-site IRMA-like sandwich assay experiments with a chessboardlike matrix of antibody pairs tested for their ability to simultaneously bind hCG $\beta$ (99/650) for hCG $\beta$-mAbs (a) and hCG (99/688) for holo hCG-mAbs (b) (NRH). Reference Abs for epitopes $\beta_{1}-\beta_{9}$ and $c_{1}-c_{4}$ served as ${ }^{125}$ I-labeled detection reagents, respectively. Reaction profiles of the solid-phase ISOBMii mAbs with the detection reference mAbs were cross-matched to that of solid-phase reference mAbs the molecular epitope specificity of which had previously been defined [1]. Similar reaction profiles were interpreted as epitope identity or neighborhood of mAbs. a The compatibility patterns of pairs of mAbs do not only reveal epitope affiliation of single mAbs but also disclose hCG $\beta$ epitope arrangement in larger antigenic domains consisting of one or more epitopes. Abs directed against epitopes located within the same antigenic domain are generally mutually exclusive in hCG $\beta$ recognition, whereas those the epitopes of which are located in different domains are compatible. Three major antigenic domains were identified on hCG $\beta$ : (1) the domain on the tips of hCG $\beta$ loops $1+3$ encompassing epitopes $\beta_{2}-\beta_{6}(2)$ the cystine knot associated domain including hCG specific epitope $\beta_{1}$, hCG $\beta+$ hCG $\beta$ cf specific epitope $\beta_{7}$, and a structurally related hCG $\beta$-only specific epitope epitope $\beta_{14}$ located on core hCG $\beta 1-112$ and characterized by a single mAb, and (3) hCG $\beta$ CTP epitopes $\beta_{8}$ and $\beta_{9}$ remote from the other domains. MAbs against all hCG $\beta$ loops $1+3$ associated epitopes $\beta_{2}-\beta_{6}$ are compatible with the hCG-specific cystine knot-associated epitope $\beta_{1}$ and vice versa. Within antigenic domains not all epitopes can be discerned by distinct reaction profiles. As an example, although $\beta_{1}$ and $\beta_{7}$ show identical patterns in sandwich assays and are not compatible with each other, they are definitely recognizing different but adjacent epitopes as $\beta_{1}$-mAbs are pan-hCG $\beta-\mathrm{mAbs}$ recognizing a broad spectrum of hCG-variants and in contrast $\beta_{7}-\mathrm{mAbs}$ are highly selective for $\mathrm{hCG} \beta+\mathrm{hCG} \beta \mathrm{cf}$ and would not recognize, e.g., hCG (see, e.g., DB-RIA, Fig. 4). A second example are mAbs against epitopes $\beta_{4}$ (ISOBM-419 and ISOBM-445) and $\beta_{5}$ (ISOBM-428, ISOBM-429, ISOBM-430, ISOBM-431, and ISOBM442) having an identical compatibility profile, i.e., nicely work with mAbs against epitopes $\beta_{1}$ and $\beta_{7-9}$ but not with $\beta_{2}-\beta_{6}$. These epitopes can be discerned by their variant recognition profiles whereby $\beta_{4} \mathrm{mAbs}$ are specific for hCG $(\leq 1 \%$ cross-reactivity with $\mathrm{hLH})$ and $\beta_{5} \mathrm{mAbs}$ strongly cross-react with $\mathrm{hLH}(>>1 \%)$ in titration and competitive RIA (Fig. 4). $\beta_{3}$-mAbs, although showing a similar reaction pattern as other mAbs directed to hCG $\beta$ loops $1+3$ associated epitopes $\left(\beta_{2}, \beta_{4}, \beta_{5}\right.$, and $\beta_{6}$ ), seems to be remote from the free subunit specific epitope $\beta_{6}$ and not compatible with hCG $\beta$ CTP113-116 located epitope $\beta_{9}$ at the beginning of hCG $\beta C T P$. Such spatial vicinity between the hCG $\beta C T P$ and hCG $\beta$ loop 3 has already been postulated previously [72]. As expected, the epitope of $\beta_{8}$-mAbs located at the very carboxyl-terminal end of hCG $\beta$ (aa hCG $\beta 141-144$; [24]) is compatible with all other epitopes. In the first ISOBM TD-7 WS, a new epitope $\beta_{14}$ was observed represented by a single $\mathrm{mAb}$ (ISOBM-267) that exclusively recognized core hCG $\beta$ [1] and that now appeared compatible with all hCG $\beta$ located epitopes except for epitope $\beta_{1}$, thus seems to be remote from any other core $\mathrm{hCG} \beta$ epitope. ISOBM-406 according to its sandwich pattern (no compatibility with cystine knot epitopes $\beta_{1}$ and $\beta_{7}$ ) seems to be cystine knot associated. $\mathbf{b}$ c-mAbs show variant reaction patterns among themselves. The heterodimeric epitopes $\mathrm{c}_{1}-\mathrm{c}_{3}$ are located in the same antigenic domain thus are not compatible with each other. $c_{4}$ is clearly remote from that domain as it is compatible with $c_{1}$ to $c_{3}-m A b s$. ISOBM-433 recognizes a previously structurally not defined epitope that is highly hCG specific as is ISOBM-446 (epitope $c_{3}$ ) (Fig. 4). ISOBM-389 a highly hCG specific c-mAb that according to BIAcore ${ }^{\circledR}$ analyses rapidly dissociates $\left(K_{\mathrm{d}}=13 \mathrm{E}-03\right)$, ISOBM-397 and ISOBM418 (very low affinity in FRET analyses) did not perform well as capture mAbs in this type of assay and were negative throughout (not shown). Reactions classified as positive (mean +2 standard deviations) are depicted as closed squares. Noncompatible mAb pairs are shown as white squares 
a

\begin{tabular}{|c|c|c|c|c|c|c|c|c|c|c|c|c|}
\hline \multirow[t]{3}{*}{$\mathbf{a}$} & & \multicolumn{9}{|c|}{ Tracer mAbs } & \multirow[b]{3}{*}{ Epitope } & \multirow[b]{3}{*}{ Domain } \\
\hline & \multirow[b]{2}{*}{$\begin{array}{c}\text { ISOBM } \\
\text { Code }\end{array}$} & $\beta_{1}$ & $\boldsymbol{\beta}_{2}$ & $\beta_{3}$ & $\beta_{4}$ & $\boldsymbol{\beta}_{5}$ & $\beta_{6}$ & $\boldsymbol{\beta}_{7}$ & $\beta_{8}$ & $\beta_{9}$ & & \\
\hline & & 莡 & 苂 & \&ั & 莡 & $\stackrel{*}{\text { \& }}$ & 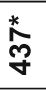 & 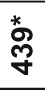 & 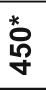 & $\stackrel{*}{*}$ & & \\
\hline \multirow{41}{*}{ 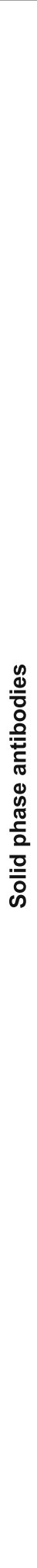 } & 382 & & & & & & & & & & \multirow{10}{*}{$\boldsymbol{\beta}_{2}$} & \multirow{26}{*}{ 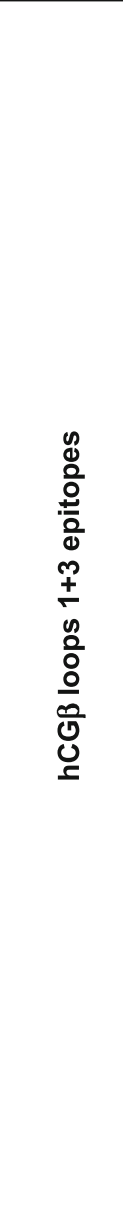 } \\
\hline & 388 & & & & & & & & & & & \\
\hline & 390 & & & & & & & & & & & \\
\hline & 402 & & & & & & & & & & & \\
\hline & 416 & & & & & & & & & & & \\
\hline & 417 & & & & & & & & & & & \\
\hline & 426 & & & & & & & & & & & \\
\hline & $449^{*}$ & & & & & & & & & & & \\
\hline & 408 & & & & & & & & & & & \\
\hline & 427 & & & & & & & & & & & \\
\hline & 419 & & & & & & & & & & \multirow{2}{*}{$\beta_{4}$} & \\
\hline & $445^{*}$ & & & & & & & & & & & \\
\hline & $428 s^{1)}$ & & & & & & & & & & \multirow{5}{*}{$\boldsymbol{\beta}_{5}$} & \\
\hline & 429s & & & & & & & & & & & \\
\hline & $430 \mathrm{~s}$ & & & & & & & & & & & \\
\hline & $442^{*}$ & & & & & & & & & & & \\
\hline & $431 \mathrm{~s}$ & & & & & & & & & & & \\
\hline & 396 & & & & & & & & & & \multirow{7}{*}{$\boldsymbol{\beta}_{3}$} & \\
\hline & 423 & & & & & & & & & & & \\
\hline & 399 & & & & & & & & & & & \\
\hline & 400 & & & & & & & & & & & \\
\hline & 401 & & & & & & & & & & & \\
\hline & 405 & & & & & & & & & & & \\
\hline & $441^{*}$ & & & & & & & & & & & \\
\hline & 410 & & & & & & & & & & \multirow{2}{*}{$\beta_{6}$} & \\
\hline & $437^{*}$ & & & & & & & & & & & \\
\hline & 403 & & & & & & & & & & \multirow{2}{*}{$\beta_{1}$} & \multirow{9}{*}{ 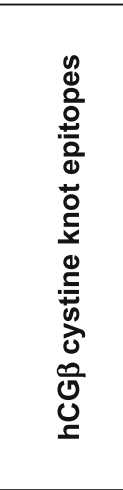 } \\
\hline & $435^{*}$ & & & & & & & & & & & \\
\hline & 386 & & & & & & & & & & \multirow{5}{*}{$\beta_{7}$} & \\
\hline & 407 & & & & & & & & & & & \\
\hline & 409 & & & & & & & & & & & \\
\hline & 415 & & & & & & & & & & & \\
\hline & $439^{*}$ & & & & & & & & & & & \\
\hline & 406 & & & & & & & & & & $\beta$ & \\
\hline & 267 & & & & & & & & & & $\beta_{14}$ & \\
\hline & $450 *$ & & & & & & & & & & \multirow{4}{*}{$\beta_{8}$} & \multirow{6}{*}{ 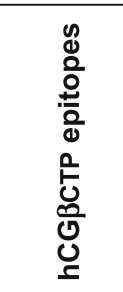 } \\
\hline & 395 & & & & & & & & & & & \\
\hline & 413 & & & & & & & & & & & \\
\hline & 420 & & & & & & & & & & & \\
\hline & 392 & & & & & & & & & & $\beta_{\text {CTP? }}$ & \\
\hline & 394 & & & & & & & & & & $\beta_{9}$ & \\
\hline
\end{tabular}




\begin{tabular}{|c|c|c|c|c|c|c|}
\hline \multirow[t]{3}{*}{ b } & & \multicolumn{4}{|c|}{ Tracer mAbs } & \multirow[b]{3}{*}{ Epitope } \\
\hline & & $c_{1}$ & $c_{2}$ & $c_{3}$ & $\mathrm{C}_{4}$ & \\
\hline & $\begin{array}{c}\text { ISOBM } \\
\text { No }\end{array}$ & $\stackrel{*}{\&}$ & $\begin{array}{l}\text { + } \\
\infty \\
\text { m }\end{array}$ & $\stackrel{*}{\circ}$ & 苂 & \\
\hline \multirow{13}{*}{ 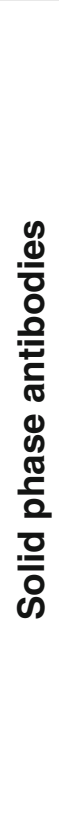 } & 414 & & & & & \multirow{2}{*}{$c_{1}$} \\
\hline & $447^{*}$ & & & & & \\
\hline & 387 & & & & & \multirow{6}{*}{$c_{2}$} \\
\hline & 411 & & & & & \\
\hline & 422 & & & & & \\
\hline & 425 & & & & & \\
\hline & $436^{*}$ & & & & & \\
\hline & $438^{*}$ & & & & & \\
\hline & & & & & & \\
\hline & $446^{*}$ & & & & & $c_{3}$ \\
\hline & $424^{a)}$ & & & & & \multirow{2}{*}{$\mathrm{C}_{4}$} \\
\hline & $440^{*}$ & & & & & \\
\hline & 433 & & & & & C \\
\hline
\end{tabular}

*...reference mAbs

1) S: sheep

Fig. 6 (continued)

are pan hCG specific, i.e., present on hCG, hCGn, hCG $\beta$ hCG $\beta$ n, and hCG $\beta$ cf (Fig. 4a), whereas $\beta_{6}$ is present only on $\mathrm{hCG} \beta, \mathrm{hCG} \beta \mathrm{n}$, and hCG $\beta \mathrm{cf}$.

The cystine knot-associated antigenic domain comprises a number of epitopes that are recognized by 10 of the $48 \beta$ mAbs (including ISOBM-397 results of which are ambiguous). ISOBM-267 that is $\mathrm{hCG} \beta$ specific and its epitope cystine knot-related (epitope $\beta_{14}$ ) was used as a control $\mathrm{mAb}$ : The pan-hCG epitope, $\beta_{1}$ (hCG $\beta$ Arg10, Arg60, and Gln89), which is not shared by $\mathrm{hLH}$, was recognized by two ISOBM-mAbs (ISOBM-403 and reference mAb ISOBM435). It is spatially close to epitope $\beta_{7}$ (hCG $\beta$ Asp61 and Gln89) against which six mAbs (including ISOBM-397) were directed. MAbs classified as $\beta_{7}$ recognize either hCG $\beta+$ hCG $\beta n+$ hCG $\beta$ cf or mainly hCG $\beta+$ hCG $\beta$ n (ISOBM-407). The cystine knot-related epitope $\beta_{10}$ recognized by reference $\mathrm{mAb}$ ISOBM-448 is hCG $\beta \mathrm{cf}$ specific. One mAb (ISOBM406) reacted with a not specified cystine knot epitope (Fig. 6a). This mAb is of restricted pan-hCG specificity and does not recognize hCG $\beta c f$ (Fig. 4a).

In addition to the above-mentioned mAb ISOBM-448 (cystine knot related epitope $\beta_{10}$ ), 4 of the $48 \beta$-Abs recognize epitopes located on hCG $\beta$ cf only (epitope $\beta_{11}$, ISOBM-384 and ISOBM-444; epitope $\beta_{13}$, ISOBM-443; and one noncoded hCG $\beta$ cf epitope, ISOBM-393).

Six of the $48 \beta$-Abs are directed against the hCG $\beta C T P$. The linear antigenic region (aa hCG $\beta 137-144$; epitope $\beta_{8}$ ) at the very end of the hCG $\beta C T P$ is recognized by four mAbs; type 2). Three of these (ISOBM-395, ISOBM-413, and ISOBM-420) are mAbs against epitope $\beta_{8,2}$ recognizing glycosylated hCG $\beta$ much better than the nonglycosylated synthetic peptide. Thus, epitope $\beta_{8,2}$ might be influenced by glycans on Ser132 and/or Ser138 [1, 39]. One mAb (ISOBM-450; epitope $\beta_{8,1}$ ) recognizes both antigens to the same extent. Two mAbs, 394 and 418, may be directed against epitope $\beta_{9}$. One $\beta$-mAb (ISOBM-392) could not be classified but it does not seem to be located on hCG $\beta$ CTP (Figs. 4a and 7a).

Thirteen of the $69 \mathrm{mAbs}$ reacted with c-epitopes: $c_{1}$ $(n=2), \mathrm{c}_{2}(n=6), \mathrm{c}_{3}(n=1), \mathrm{c}_{4}(n=2), \mathrm{c}(n=1 ;$ ISOBM-433; new noncoded c-epitope). One c-mAb could not be classified (ISOBM-389).

Eight out of $69 \mathrm{mAbs}$ are directed against $\mathrm{hCG} \alpha$. Six recognize assembled and one, ISOBM-404, which has been prepared by immunization with $\mathrm{hCG} \alpha$ (Stenman et al., unpublished data), recognizes only free $\mathrm{hCG} \alpha$. The exact molecular localization of the $\mathrm{hCG} \alpha \mathrm{mAbs}$ was not elucidated (Figs. $4 \mathrm{~b}$ and $7 \mathrm{~b}$ ).

\section{Discussion}

Topography of hCG epitopes

\section{Epitopes and antibodies}

By definition, epitopes are molecular structures dependent on the existence of complementary Abs. Not the entire surface of a glycoprotein like hCG is antigenic. Against certain molecular areas no Abs exist as they are immunologically inert, e.g., due to insufficient $\mathrm{T}$ cell help, or sterically not accessible due to protein folding or shielding by glycans. In contrast, other areas representing structurally inherent epitopes, which are characterized by high solvent accessibility and high protrusion indices, are often sites of $\mathrm{Ab}$ recognition [40]. hCG $\beta$ cystine knot-associated residues Arg10 and Gln89 (epitopes $\beta_{1}$ and $\beta_{7}$ ), hCG $\alpha$ loop 1 residues Pro16, Phe17, and Phe 18 (epitopes $\alpha_{1}, \alpha_{2}$,and $\alpha_{4}$ ) and the antigenic domain on hCG $\beta$ loops $1+3$ comprising aa 20 $25+68-75$ (epitopes $\beta_{2}-\beta_{6}$ ) all bulge away from the molecule forming prominent surfaces that are the major antigenic domains of hCG [3, 22, 37, 41-43]. There is a good chance that irrespective of the immunized species these molecular structures will be recognized as epitopes [38]. For example, 
Table 5 Epitope assignment of the ISOBM-Abs using three approaches

\begin{tabular}{|c|c|c|c|c|c|}
\hline Epitopes & $\mathrm{n}$ & Comments & Classi & ication of ISOBM-mAbs by three & approaches \\
\hline$\beta-m A b s^{a}$ & 48 & & Antigen binding (NRH) & Affinity (FRET) (ABB) & Sandwich assay (NRH) \\
\hline$\beta_{1}$ & 2 & Specific for $h C G$ and $h C G$ derivatives & $403,435^{*}$ & $403,435^{\star}$ & $403,435^{*}$ \\
\hline$\beta_{2}, \beta_{4}$ & 12 & $\begin{array}{l}<1 \% \text { cross-reactivity with } \mathrm{hLH} / \mathrm{hLH} \beta \\
\text { Epitopes located on top of loops } 1+3\end{array}$ & $\begin{array}{l}\beta_{2}: 382,388,390,402,408, \\
416,417,426,427,449^{*} \\
\beta_{4}: 419,445^{*}\end{array}$ & $\begin{array}{l}\beta_{2}: 382,388,390,402,408, \\
416,417,426,427,449^{\star} \\
\beta_{4}: 419,445^{\star}\end{array}$ & $\begin{array}{l}\beta_{2}: 382,388,390,402,408,416, \\
417,426,427,449^{\star} \\
\beta_{4}: 419,445^{\star}\end{array}$ \\
\hline$\beta_{3}, \beta_{5}$ & 13 & $\begin{array}{l}\text { High cross-reactivity with } \mathrm{hLH} / \mathrm{hLH} \beta \\
\text { Epitopes located on top of loops } 1+3\end{array}$ & $\begin{array}{l}\beta_{3}: 396,399,400,401,405, \\
424,434,441^{*} \\
\beta_{5}: 428 \text { s to } 431 \mathrm{~s}, 442^{*}\end{array}$ & $\begin{array}{l}\beta_{3}: 396,399,400,401,405, \\
424,434,441 \\
\beta_{5}: 428 \text { s to } 431 s, 442^{*}\end{array}$ & $\begin{array}{l}\beta_{3}: 396,399,400,401,405,424, \\
434,441^{*} \\
\beta_{5}: 428 \mathrm{~s} \text { to } 431 \mathrm{~s}, 442^{*}\end{array}$ \\
\hline$\beta_{6}$ & 2 & No recognition of the $\alpha \beta$ heterodimer & 410,437 & 410,437 & 410,437 \\
\hline$\beta_{7}$ & 6 & No recognition of the $\alpha \beta$ heterodimer & $386,397,407,409,415,439$ & $386,397,407,409,415,439$ & $386,407,409,415,439$ \\
\hline$\beta_{8}$ & 4 & Epitope on hCG $\beta$ CTP & $\begin{array}{l}\text { Type 1: } 450^{*} ; \\
\text { Type 2: } 395,413,420 \\
\end{array}$ & $450^{\star}, 395,413,420$ & $450,395,413,420$ \\
\hline$\beta_{9}$ & 2 & Epitope on hCG $\beta$ CTP & 394,418 & & 394 \\
\hline$\beta_{10}-\beta_{13}$ & 5 & Specific for hCGßcf & $384,393,443^{*}, 444^{\star}, 448^{*}$ & $384,444^{*}$ & n.d. \\
\hline$\beta$ & 2 & Unspecified location & 392,406 & & 392, 406 (cystine knot?) \\
\hline$\alpha \beta$-mAbs ${ }^{b}$ & 13 & & & & \\
\hline $\mathrm{c}_{1}$ & 2 & In a cluster with $\mathrm{c}_{2}$, sensitive to nicks & $414,447^{*}$ & $414,447^{*}$ & $414,447^{*}$ \\
\hline $\mathrm{C}_{2}$ & 6 & In a cluster with $\mathrm{c}_{1}$, sensitive to nicks & $387,411,422,425,436^{*}, 438^{*}$ & $387,411,422,425,436^{\star}, 438^{*}$ & $387,411,422,425,436^{*}, 438^{*}$ \\
\hline $\mathrm{c}_{3}$ & 1 & Specific for hCG + hCGn & $446^{*}$ & $446^{*}$ & $446^{*}$ \\
\hline $\mathrm{c}_{4}$ & 2 & Spatially remote from other epitopes & $424,440^{*}$ & $424,440^{*}$ & $424,440^{*}$ \\
\hline $\mathrm{c}$ & 2 & Unspecified location & 389,433 & 389 & 433 \\
\hline$\alpha-m A b s^{c}$ & 8 & Not epitope typed in detail & $\begin{array}{l}383,385,391,398,404,412, \\
421,432\end{array}$ & & \\
\hline$\alpha_{3}$ & 1 & Epitope sensitive to iodination & $432 ?$ & & \\
\hline$\alpha_{6}$ & 1 & Specific for non-combined hCG $\alpha$ & $404 ?$ & & \\
\hline Excluded $A$ & & & None & $\begin{array}{l}383^{\mathrm{d}}, 385^{\mathrm{d}}, 391^{\mathrm{d}}, 398^{\mathrm{d}}, 404^{\mathrm{d}}, \\
412^{\mathrm{d}}, 418^{\mathrm{d}}, 421^{\mathrm{d}}, 432^{\mathrm{d}}, 443^{\star \mathrm{d}}, \\
448^{\star \mathrm{d}}\end{array}$ & $\begin{array}{l}383,384,385,389^{\mathrm{e}}, 391,393,397, \\
398,404,412,418^{\mathrm{e}}, 421,432^{\mathrm{e}}, \\
434^{\mathrm{e}}, 443^{\star}, 444^{\star}, 448^{\star}\end{array}$ \\
\hline Fourteer & & 13 of which recognized by IS & M-mAbs & & \\
\hline${ }^{b}$ At least fo & ur ep & itopes; four plus one recognized by & ISOBM-mAbs & & \\
\hline${ }^{c}$ Seven epit & opes & these ISOBM-mAbs were not char & acterized in detail & & \\
\hline${ }^{\mathrm{d}}$ Specificity & base & $d$ on affinity for $h C G, h C G \beta$ and $h$ & CG $\beta$ cf could not be detern & & \\
\hline${ }^{\mathrm{e}}$ These four & ISO & BM-mAbs did not perform well as & apture reagents & & \\
\hline eference & $\mathrm{mAb}$ & & & & \\
\hline
\end{tabular}

the immunodominant antigenic domain on top of hCG $\beta$ beta-sheet loops 1 and 3 is recognized by Abs derived from mice and sheep as shown in the present study and interestingly by Abs from humans and rabbits (PB, unpublished observations). Moreover, hLH cross-reactive mAb B206 directed against an epitope within this cluster, presumably epitope $\beta_{3 / 5}$, inhibited $40-90 \%$ of the binding of human antisera to hCG [44].

The definition of epitopes by Abs and recognition of the multitudes of possible amino acid combinations within an inherently antigenic structure/domain is dependent on and restricted by the combinatorial repertoire of the VDJ and VJ immunoglobulin heavy and light chains gene segments, respectively, and the cellular capacity to mature the paratope of a given $\mathrm{Ab}$ to optimally fit the antigenic surface. This repertoire of $\mathrm{Ab}$ specificity varies with individual immune responses, haplotypes, and species. Not every amino acid combination within an antigenic domain will therefore be recognized by Abs of any individual or species. Thus, the repertoire of $\mathrm{Ab}$ specificities and corresponding epitopes within an antigenic domain is very large but still somewhat restricted as shown by the present and previous studies. For example, the antigenic domain on hCG $\beta$ loops $1+3$ is recognized by large panels of Abs that differ slightly in hCG variant recognition, hLH cross-reactivity, affinity, etc. This has been shown to be due to variability in amino acid recognition within the antigenic domain [1].

It is striking that this antigenic region, aa hCG $\beta 20$ $25+68-75$ on the tips of loops $1+3$, comprises 16 amino acids, a number that reasonably well corresponds to the surface covered by a single complementary paratope of an $\mathrm{Ab}$ whereby two to three amino acids that vary from $\mathrm{Ab}$ to $\mathrm{Ab}$ provide most of the binding energy and fine specificity [45]. Consequently, dozens of ISOBM-mAbs and Abs of other panels directed against hCG $\beta$ loops $1+3$ epitopes $\beta_{2}-\beta_{5}$ do not behave uniformly in their recognition of the approximately 15 potential contact amino acids composing discontinuous epitopes, even though they cover more or less the same surface with their paratope [43]. Thus, all differences in affinity, specificity, and hLH cross-reactivity of numerous antibodies directed against this major antigenic region seem to have their basis in variability of preferential 


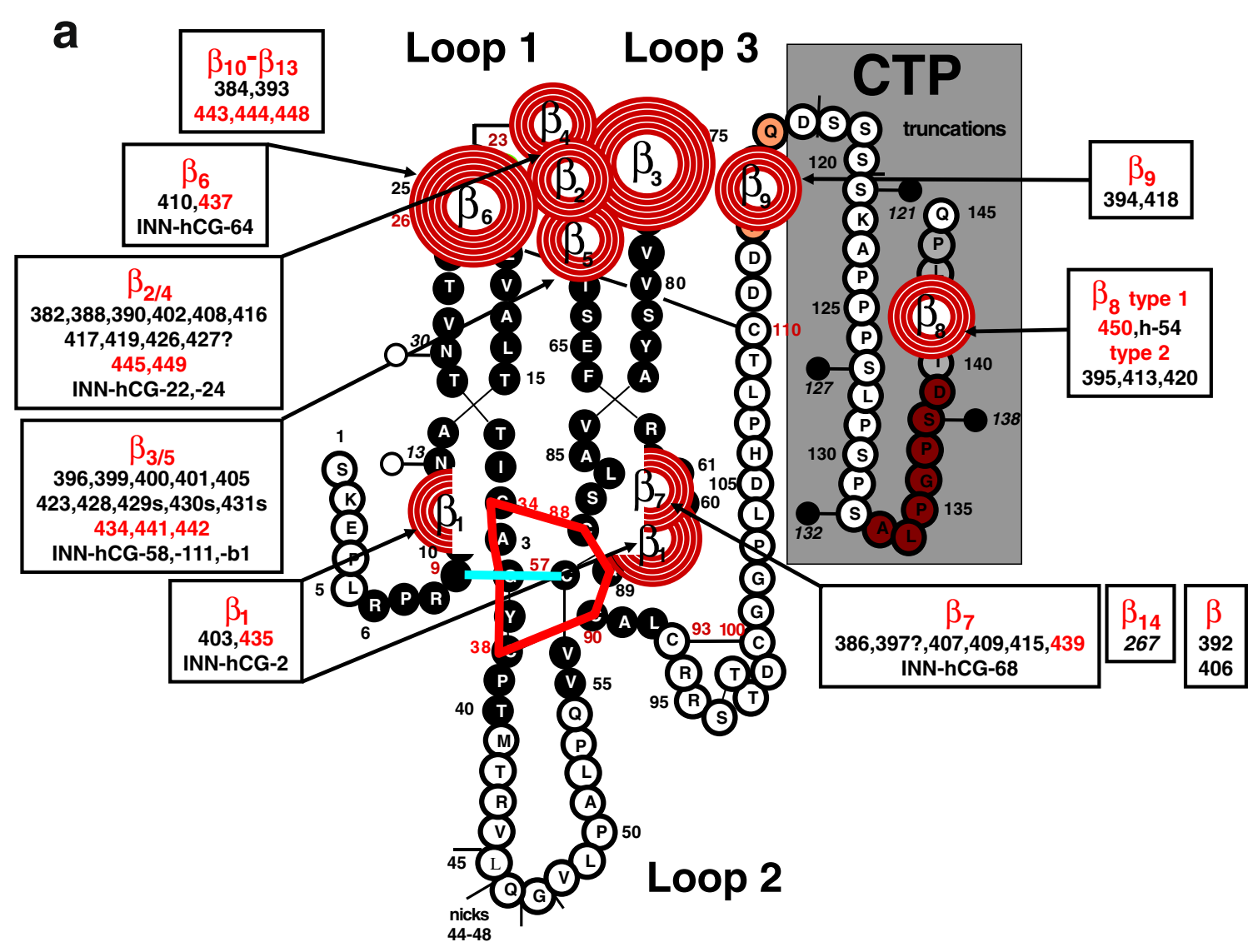

b

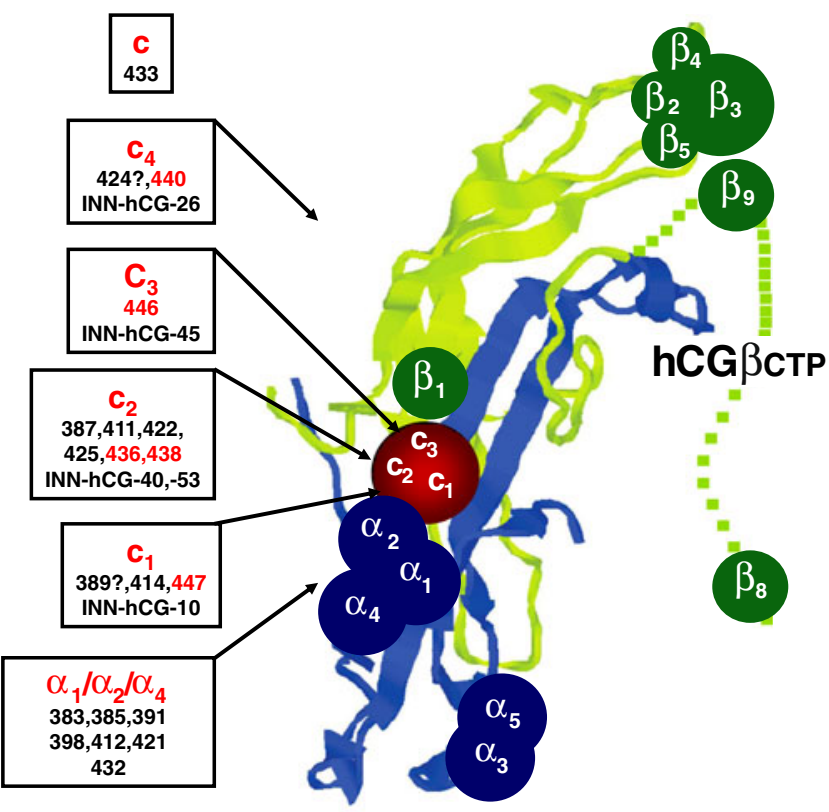

recognition of a few amino acids, providing binding energy within very similar or even identical sets of amino acids covered by the Abs' paratopes.
The surface area of an epitope that is covered by a cylinder-like antigen binding site of an $\mathrm{Ab}$ is approximately $700 \AA^{2}$ in size $[38,46]$, whereby the radius of the antibody 
4Fig. 7 Epitope maps of hCG, hCG $\beta$, and variants (INN) (modified according to [1], with permission) were previously constructed based on the epitopes recognized by the reference mAbs. The identification of reference $\mathrm{mAb}$ epitopes was performed by direct binding, competitive and sandwich RIA and ELISA with hormones of various species, hormones subunits, metabolic breakdown products, and synthetic peptides (for reviews, see [1, 22]). Furthermore, on the basis of molecular modeling of crystallographic data of hCG and subsequent mutational analyses to assign epitopes to particular amino acids, epitopes of reference mAbs and, by comparison, epitopes of ISOBM-mAbs could be superimposed on the molecular model of hCG $\beta$. a Assignment of ISOBM-mAbs to epitopes on the molecular model of hCG $\beta / \mathrm{hCG} \beta \mathrm{n} / \mathrm{hCG} \beta \mathrm{cf} / \mathrm{hCG} \beta \mathrm{CTP}$. Reaction profiles of the ISOBMii mAbs in specificity and sandwich assays were compared to that of reference mAbs. It appeared that the most immunogenic region of $\mathrm{hCG} \beta$ is determined by the peptide sequences that correspond to hCG $\beta \mathrm{cf}$. In particular, the tips of beta-sheet loops $1+3$ corresponding to $\mathrm{hCG} \beta 20-25+68-77$ comprise the major antigenic domain (epitopes $\beta_{2}-\beta_{6}$ ) that is recognized by high affinity $\mathrm{mAbs}$. The only hCG-specific epitope on core hCG $\beta$ is $\beta_{1}$ located around the center of the molecule corresponding to part of the cystine knot (aa hCG $\beta 10,60,89)$. Adjacent to epitope $\beta_{1}$, the hCG $\beta /$ hCG $\beta$ cf-specific epitope $\beta_{7}$ is also located in this region (aa hCG $\left.\beta 61,89\right)$ [43]. Thus, pairs of antibodies against these two epitopes are not compatible in sandwich type assays (Fig. 6a) [24]. hCG $\beta$ CTP epitopes $\beta_{9}$ and $\beta_{8}$ are located at either end of the hCG $\beta C T$, whereby $\beta_{9}$ might be close to epitope $\beta_{3}$ (Fig. 6a) [72]. b Epitope map of hCG. ISOBM-mAbs were assigned to epitopes on a ribbon representation of the molecular model of hCG [3]. $\mathrm{hCG} \alpha$ and epitopes thereon are depicted in blue, $\mathrm{hCG} \beta$ and its epitopes in green. Conformationally (c) dependent epitopes determined by the quaternary structure of hCG are shown in red. Note the major antigenic clusters of epitopes on the top of beta sheet loops 1 and 3 of $\operatorname{hCG} \alpha\left(\alpha_{1} /\right.$ $\alpha_{2} / \alpha_{4}$ and $\left.\alpha_{3} / \alpha_{5}\right)$ and of hCG $\beta\left(\beta_{2}-\beta_{5}\right)$, the central cystine knot-based epitope cluster encompassing highly hCG-specific $\beta_{1}$ and c-epitopes $\left(c_{3}\right)$, the latter having a share on loop 2 of hCG $\beta$, that in turn are confluent with the $\alpha_{1} / \alpha_{2} / \alpha_{4}$ epitope cluster. The hCG $\beta$ CTP epitopes are located on both of its ends at aa hCG $\beta 113-116$ (epitope $\beta_{9}$ ) and aa hCG $\beta 133-144$ (epitope $\beta_{8}$ )

binding domain is $8-10 \AA$ and the radius of the epitope covering area is $15 \AA$ irrespective of Ab specificity [45]. Xray crystallography studies revealed that core $\mathrm{hCG}$, i.e., $\mathrm{hCG}$ without hCG $\beta$ CTP, has a length of $75 \AA$ and a width of 30 $35 \AA[3,47]$ corresponding to a surface area of approximately $8,200 \AA^{2}$. As some regions on assembled hCG $\beta$, such as the stems of $\beta$-sheet loops $1+3$, are not recognized by any antihCG-mAbs [1, 18, 48], the total epitope-covered area on core hCG could be in the range of 5,000 $\AA^{2}$ theoretically accommodating simultaneous binding of up to seven Abs to spatially independent epitopes. The minimal spatial requirement for sterical compatibility of two mAbs is that the respective epitopes are approximately $20-30 \AA$ apart. In fact preliminary experiments showed that at least five radiolabeled $\mathrm{mAbs}$ against epitopes $\beta_{1}+\beta_{3}+\alpha_{2}+\alpha_{3}+c_{4}$ were able to bind to core hCG simultaneously [38].

\section{Glycosylation and epitopes}

With two exceptions, glycosylation has little effect on hCG's immunological make-up, although the glycans, which are hydrophilic in nature and thus surface exposed, represent approximately $30-35 \%$ of its total molecular mass. The exceptions are glycans at the very end of hCG $\beta C T P$ and in the stem region of hCG $\beta$ loop 1 . The 14 epitopes on core hCG, which is lacking hCG $\beta C T P$, are dependent on the protein backbone. Neither desialylation, deglycosylation [48], partial natural deglycosylation as in the case of the metabolic product hCG $\beta \mathrm{cf}[49]$, nor intense glycosylation as shown with highly acidic $\mathrm{p} I$ variants of pregnancy- and tumor-derived hCG have essential effects on $\mathrm{Ab}$ recognition by the reference mAbs [17, 18]. In addition, the number and the relative spatial location of epitopes do not differ between the isoforms $[1,18,48]$.

The peptidic stem region of assembled hCG $\beta$ loop 1, which accommodates the two large N-linked glycans at hCG $\beta A s n 13$ and Asn 30 that are spatially near the $\mathrm{hCG} \alpha$ glycan at Asn52 [3], is not recognized by any mAb in the panels of anti-hCG-mAbs of the previous and the present study. Thus, the immune response seems to be attenuated by the $\mathrm{N}$-linked glycans in this region of $\mathrm{hCG} \beta$ loop 1 $[1,18,48]$.

A mAb (B152) that was not included in this study recognizes hCG with a core-2 O-glycan at Ser 132 and surrounding peptide structures [50, 51]. Its epitope, which we termed $\beta_{8,3}$, is spatially related to epitope $\beta_{8,2}$ that also seems to be influenced by the glycans on Ser 132 and/or Ser $138[1,29]$.

Some hCG assays have been claimed to underestimate hCG-h [52]. However, these results have been obtained with an hCG-h preparation that also was completely nicked (C5) [39]. Thus, the results most probably reflected failure to recognize hCGn rather than hyperglycosylated hCG.

\section{Epitopes on assembled and/or free $h C G \beta\left(\beta_{1}-\beta_{9}, \beta_{14}\right)$ and $h C G \beta c f$ only $\left(\beta_{10}-\beta_{13}\right)$}

The immunodominant structure of $\mathrm{hCG}$ and $\mathrm{hCG} \beta$-related molecules is the molecular region corresponding to $\mathrm{hCG} \beta \mathrm{cf}$, which has lost its $\mathrm{N}$-terminus, the long loop 2, most of its $\mathrm{N}$ linked carbohydrate antennae, and the hCG $\beta C T P$ with all Olinked glycans but has retained its protein backbone configuration [53]. Thus, numerous mAbs against epitopes $\beta_{1}-\beta_{7}$ recognize $\mathrm{hCG} \beta, \mathrm{hCG} \beta \mathrm{n}$, and $\mathrm{hCG} \beta \mathrm{cf}$. However, one $\mathrm{mAb}$ (ISOBM-407) did not react with hCG $\beta c f$.

The epitopes on assembled and/or free hCG $\beta\left(\beta_{1}-\beta_{9}\right.$, $\beta_{14}$ ) are located in three molecular regions: (1) hCG $\beta$ cystine knot, (2) tips of hCG $\beta$ loops $1+3$, and (3) hCG $\beta$ CTP.

The cystine knot-associated antigenic domain includes epitope $\beta_{1}$ involving aa $\mathrm{hCG} \beta \operatorname{Arg} 10+\operatorname{Arg} 60$ and possibly Gln 89 that sterically are in close proximity to each other [42, 43]. hCG $\beta \operatorname{Arg} 10$ and $\operatorname{Gln} 89$ are unique to $\mathrm{hCG}$ and not shared by hLH. This presumably explains why epitope $\beta_{1}$ is highly specific for hCG and its variants and therefore is not 
Table 6 hCG and/or hCG-variants measurements: candidate epitopes for sandwich methods (modified according to [1])

\begin{tabular}{|c|c|c|c|}
\hline Primary Target & $\begin{array}{c}\text { Epitope } \\
\text { Localization } \\
1^{\text {st }} \mathrm{mAb}^{\mathrm{a}}\end{array}$ & $\begin{array}{c}\text { Epitope } \\
\text { Localization } \\
2^{\text {nd }} \mathrm{mAb}^{\mathrm{a}}\end{array}$ & $\begin{array}{l}\text { Appropriate } \\
\text { Clinical use }\end{array}$ \\
\hline $\begin{array}{l}\text { hCG }+ \text { hCG } \beta \\
\text { Wide spectrum of } \\
\text { hCG } \beta \text { variants }\end{array}$ & $\begin{array}{c}\beta_{1} \text { cystine knot } \\
h C G \beta 10+60+89\end{array}$ & \multirow{4}{*}{$\begin{array}{c}\beta_{2} \\
\text { hCG } 1 \text { loops } 1+3 \\
\text { aa } 20-25+68-77\end{array}$} & $\begin{array}{c}\text { Oncology } \\
\text { Early pregnancy } \\
\text { Prenatal screening }\end{array}$ \\
\hline hCG & $\begin{array}{c}\mathrm{C}_{2} \text { or } \mathrm{C}_{3} \\
h C G \beta \text { loop } 2 \\
\text { cystine knot } h C G \beta, \\
h C G \alpha \text { loop1 }\end{array}$ & & $\begin{array}{c}\text { Oncology } \\
\text { Early pregnancy } \\
\text { Prenatal screening } \\
\text { hCG } \beta \text { det. necessary }\end{array}$ \\
\hline $\mathrm{hCG} \beta$ & $\begin{array}{c}\beta_{7} \text { cystine knot } \\
h C G \beta 61+89\end{array}$ & & $\begin{array}{c}\text { Oncology } \\
\text { Prenatal screening } \\
\text { hCG det. mandatory }\end{array}$ \\
\hline hCG $\beta c f$ & $\begin{array}{c}\beta_{11} \\
\text { hCG } \beta \text { cf }\end{array}$ & & $\begin{array}{l}\text { Clinical utility to be } \\
\text { established } \\
\text { In urine only }\end{array}$ \\
\hline $\mathrm{hCG} \alpha$ & $\begin{array}{c}\alpha_{6} \\
h C G \alpha 33-42\end{array}$ & $\begin{array}{c}\alpha_{5} \\
\text { Loop } 3 \text { (Tyr 65) }\end{array}$ & $\begin{array}{c}\text { Oncology (pit./testis) } \\
\text { Clinical utility to be } \\
\text { established }\end{array}$ \\
\hline
\end{tabular}

${ }^{\mathrm{a}}$ Candidate mAbs for the respective epitopes are listed in Figs. 4, 6, 7, and Appendix 2

present on hLH or hLH $\beta$ [26]. Due to its superior specificity, it is highly valuable for $\mathrm{hCG} / \mathrm{hCG} \beta$-variant measurement by immunoassay with no interference by hLH or hLH $\beta$ [1].

The assumed location of epitope $\beta_{7}$ on hCG $\beta$, hCG $\beta$, and $\mathrm{hCG} \beta \mathrm{cf}$ is based both on mutational analyses and vicinity analysis by sandwich assays: It is associated with the cystine knot, present on hCG $\beta$ cf, and Asp61 and Gln89 have a role in this epitope. Thus, in sandwich type assays, $\beta_{7}-\mathrm{mAbs}$ are not compatible with $\beta_{1}$-mAbs (Fig. 6a) [1, 22, 24].

MAbs against the cystine knot epitope $\beta_{7}$ recognize $\mathrm{hCG} \beta \mathrm{cf}$ in addition to hCG $\beta$. ISOBM-407 is an exception to this, although other parameters match with epitope $\beta_{7}$, it shows an exceptionally low cross-reactivity with hCG $\beta \mathrm{cf}$ (Fig. 4) and thus seems to be suitable for measurement of hCG $\beta$ in urine in the presence of high levels of hCG $\beta c f$. The assignment of hCG $\beta$ specific epitope $\beta_{14}$ to the cystine knot antigenic domain is based on circumstantial evidence as mAb ISOBM-267 defined in the First ISOBM TD-7 WS to recognize epitope $\beta_{14}$ is not compatible with hCG $\beta$ cystine knot-related epitope $\beta_{1}$ but with all other hCG $\beta$-related epitopes (Fig. 6a). Two hCG $\beta$ cf epitopes $\beta_{10}$ and $\beta_{12}$ are also cystine knot-associated (PB, unpublished data). An additional cystine knot-related epitope is represented by mAb ISOBM-406.

Antibodies directed against the major hCG $\beta$ antigenic domain on loops 1 and 3 are of significantly higher affinity compared to those against other antigenic regions of hCG $\beta[1,21,54]$. MAbs against epitopes $\beta_{2}-\beta_{5}$ recognize a wide spectrum of hCG and hCG $\beta$-related variants (hCG, hCGn, hCG $\beta$, hCG $\beta$ n, and hCG $\beta c f)[1,17,18]$. MAbs against epitopes $\beta_{3}$ and $\beta_{5}$ additionally react well with $\mathrm{hLH}$ and $\mathrm{hLH} \beta$, whereas epitopes $\beta_{2}$ and $\beta_{4}$ are specific for hCG and hCG $\beta$ variants $(<1 \% \mathrm{hLH}$ and $\mathrm{hLH} \beta$ crossreactivity) and thus highly suitable for specific measurement of hCG and hCG $\beta$ variants (Fig. 4) $[1,26]$.

In summary, $\beta$-epitopes located on the protein core hCG $\beta 1-112$ are discontinuous in nature, determined by the tertiary protein structure, present on hCG $\beta \mathrm{cf}$, and arranged in antigenic domains associated with the cystine knot and on the tips of loops $1+3$. MAbs directed against these epitopes are of adequate affinity and suitable for immunoassay applications.

hCG $\beta$-related epitopes not determined by hCG $\beta$ cf or core hCG $\beta_{1-112}$ are located in two major regions on the hCG $\beta C T P$ (aa hCG $\beta 113-145$ ). The immunodominant linear antigenic region at the very end of the hCG $\beta C T P$ consists of aa hCG $\beta 133-144$ and encompasses epitope $\beta_{8}$ that is composed of epitope variants $\beta_{8,1}, \beta_{8,2}$, and $\beta_{8,3}$ ) $[29,55]$. It partially seems to be influenced by glycans on Ser132 and/or Ser138 (epitopes $\beta_{8,2}$ and $\beta_{8,3}$ ) [29] [1, 50]. One $\mathrm{mAb}$ in this WS (epitope $\beta_{8,1}$; ISOBM-450) and four mAbs in the First WS recognized nonglycosylated synthetic peptides and glycosylated hCG $\beta$ equally [1]. Epitope $\beta_{9}$ at aa hCG $\beta 113-$ 
$116[21,24]$ was recognized by two mAbs (Fig. 7a) whereby ISOBM-394 was of high and ISOBM-418 of very low affinity (Fig. 5).

When immunizing with the glycoprotein hCG, the vast majority of antibodies will be generated against composite epitopes on hCG $\alpha$ or the core region of hCG $\beta$ (aa 1-112) but only rarely against linear peptide sequences of low structural order like the hCG $\beta$ CTP. MAbs against hCG $\beta C T P$ are generally of fairly low affinity. Nevertheless, they are used in diagnostic sandwich-type immunoassays as they do not cross-react with hLH (Fig. 4).

\section{$h C G \alpha$ epitopes $\left(\alpha_{1}-\alpha_{7}\right)$}

In the panel of ISOBM-mAbs, 8 of 69 recognize hCG $\alpha$ epitopes. One of these mAbs, ISOBM-404, seems to be specific for free $h C G \alpha$, and it is speculated that it might recognize the sequence hCG $\alpha 33-42$ on the single loop 2. As no reference $\mathrm{hCG} \alpha-\mathrm{mAbs}$ (Table 2) were included, a detailed assignment of epitopes was not possible.

\section{Epitopes on the $h C G \alpha \beta$-heterodimer $\left(c_{1}-c_{4}\right)$}

At least four epitopes $\left(\mathrm{c}_{1}-\mathrm{c}_{4}\right)$ are present only on $\mathrm{hCG} \pm$ hCGn but not on either free subunit or $\operatorname{hCG} \beta \operatorname{cf}[21,26,28]$. Detailed analysis of hCG and hCGn recognition by the ISOBM-mAbs was performed by liquid chromatography mass spectrometry (LC-MS/MS) (see accompanying publication by $\mathrm{H}$. Lund). Epitopes $\mathrm{c}_{1}$ (reference $\mathrm{mAb}$ INN-hCG10) and $c_{2}$ (reference mAbs INN-hCG-40 and INN-hCG-53) are (1) dependent on intact hCG and thus sensitive to nicking of assembled hCG $\beta$ loop 2, (2) not compatible in sandwichtype assays with the cystine knot-related hCG $\beta$ epitope $\beta_{1}$ (aa hCG $\beta \operatorname{Arg} 10+\operatorname{Arg} 60$ and possibly Gln89) [38], and (3) incompatible with $m A b s$ recognizing epitope cluster $\alpha_{1}, \alpha_{2}$, and $\alpha_{4}$ [38] on loop 1 in the region of a $h C G \alpha 13-22$. Amino acids hCG $\beta 44-48$ in loop 2 and $\mathrm{hCG} \alpha$ loop 1 have been shown by X-ray crystallography to be in close proximity as the subunits are assembled in a head-to-toe fashion [3]. It is striking that in sandwich assays $\mathrm{c}_{1}$-mAbs show identical reactivity patterns as $\alpha_{1}$ - and $\alpha_{2}$-mAbs reflecting sterical epitope relatedness $[28,38]$.

MAbs against epitope $c_{3}$ are sterically related to epitope $c_{2}$, highly specific versus $\mathrm{hLH}$ as well as non-combined intact and modified subunits $(<1 \%$ cross-reactivity), not influenced by nicking of assembled hCG $\beta$ loop 2 , and thus recognize hCGn and hCG equally $[1,56]$ (Fig. 4). They are therefore highly suitable for simultaneous measurement hCG and hCGn (Table 6).

The exact molecular localization of epitope $c_{4}$ has not been resolved yet. It is present on hCGn and $\mathrm{hLH}$, remote from and thus sterically compatible with all other c-epitopes and to a minor extent determined by
hCG $\beta$ as shown by low cross-reactivity $[1,26,38]$. A variant of the $\mathrm{c}_{4}$-epitope represented by ISOBM-424 (= ISOBM-279, First ISOBM TD-7 WS) that is not shared with hLH (cross-reactivity $<0.1 \%$ ) seems to exist. A presumably fifth highly specific c-epitope has been observed in sandwich assays wherein mAb ISOBM-433 is compatible with $\mathrm{mAbs}$ to $\mathrm{c}_{1}-\mathrm{c}_{4}$ (Fig. 6b). Its molecular localization is unknown. ISOBM-389 is a c-mAb that could not be epitope typed but, according to its specificity profile analyzed by LC-MS/MS, might be a $c_{2}$ $\mathrm{mAb}$ (see accompanying publication by $\mathrm{H}$. Lund).

\section{Method-specific recognition of hCG and hCG variants}

Sandwich-type assays measuring hCG alone or in combination with free hCG $\beta$ and metabolites are used for detection of pregnancy, pregnancy-related disorders, trophoblastic disease, and various other female and male tumors [2]. Detailed knowledge of the epitopes recognized by the Abs used facilitates development of assays providing better comparability of the results between methods. It has been suggested that assays that are multifunctional with respect to clinical use should (1) recognize in an equimolar fashion $\mathrm{hCG}$ and $\mathrm{hCG} \beta$ protein backbone and glycosylation variants, (2) not cross-react with $\mathrm{hLH}$ or derivatives, and (3) not be prone to signal blunting by non-measured variants, e.g., caused by excess hCG $\beta$ cf leading to false low results [36]. This is a problem when hCG in urine is measured with sandwich assays utilizing a mAb against core $\mathrm{hCG} \beta 1-112$ in combination with an anti-hCG $\beta$ CTP $\mathrm{mAb}$ [57].

While assays measuring hCG and all hCG $\beta$-related variants are useful as first line methods, for diagnosis of pregnancy and cancer, it is often advantageous to specifically measure only selected variants [2]. Thus, specific hCG $\beta$ assays are used for first trimester Down's syndrome screening and also for diagnosis of testicular $[58,59]$ and nontrophoblastic cancers, $20-50 \%$ of which produce only hCG $\beta$ but not hCG [60-62]. However, the concentrations are mostly low, and the assays used need to be highly sensitive. Assays for hCG $\beta$ that are intended for first trimester screening of Down's syndrome need to be insensitive to interferences by an approximately 100 -fold excess of hCG and tuned to measure fairly high concentrations. They are therefore of limited utility for the diagnosis of nontrophoblastic cancers.

Elevated plasma concentrations of hCG $\beta$ are reflected by high levels of hCG $\beta \mathrm{cf}$ in urine [63], and specific assay of this form has been used for diagnosis of nontrophoblastic cancer $[62,64,65]$ and for the characterization of the First IRR for hCG $\beta$ cf [9]. However, commercial assays are not available presently. 
Candidate epitopes for measurement of hCG and hCG $\beta$

Assays specifically recognizing hCG, hCG $\beta$, and related variants can be constructed using a combination of two pan hCG $\beta$ mAbs with identical specificity profiles [66], i.e., with one partner directed against epitopes $\beta_{2}$ or $\beta_{4}$ (the hCG $\beta$ loops 1 and 3 domain) combined with a mAb-recognizing epitope $\beta_{1}$ (the hCG $\beta$ cystine knot domain; Table 6).

In the two ISOBM TD-7 WSs, 50 of 96 Abs were shown to recognize $h C G+h C G \beta$ and 23 of these did not recognize $h L H$. Theoretically, any of the five mAbs directed against epitope $\beta_{1}$ around the cystine knot could be combined with any of the 18 mAbs against epitopes $\beta_{2}$ or $\beta_{4}$ on loops $1+3$ for construction of multifunctional assays. Epitopes $\beta_{1}$ and $\beta_{2 / 4}$ are shared by all important hCG and hCG $\beta$ protein backbone variants and glycosylation isoforms including hCG-h and hCG $\beta-h[17,18]$. MAbs against these two discrete epitopes are highly specific for hCG with $<0.1$ and $<1 \%$ cross-reaction for hLH for epitopes $\beta_{1}$ and $\beta_{2 / 4}$, respectively. No other epitope combination provided assays with equally wide and identical recognition of hCG and hCG $\beta$ variants and high specificity versus $h L H$.

While Abs recognizing these epitopes provide desirable specificity, variable affinity for hCG variants (Fig. 5) may cause nonequimolar recognition of $\mathrm{hCG}$ and $\mathrm{hCG}$ variants in different methods [6]. Although assay specificity can be predicted on the basis of mAb specificity profiles and epitope recognition [66], ultimate performance can only be evaluated with the final assay. An additional source of method variability in hCG measurement that cannot be fully predicted is that of Ab synergy, which may vary between different $\mathrm{Ab}$ pairs [67].

Alternative epitopes for measurement of hCG and/or hCG $\beta$ and variants

Few manufacturers provide information about the epitope specificities of Abs used in their assays, but due to variable recognition of the First IRR preparations for hCG and variants, it is obvious that different epitope combinations are used in the major commercial assays [6]. In addition to the epitope combination $\beta_{1}-\beta_{2 / 4}$, other combinations are possible for the construction of assays for hCG and variants, e.g., epitopes $\beta_{8,1}$ and $\beta_{2}, \beta_{1}-\alpha_{5}, \alpha_{4}-\beta_{2}$, etc., but none of them will fulfill all three above-mentioned criteria. However, the frequently used $\beta_{8}$ and $\beta_{2}$ combination does not pose problems as long as serum specimen are measured that do not contain $\mathrm{hCG} \beta \mathrm{cf}$, truncated hCG or truncated hCG $\beta$, or clipped hCG $\beta C T P$.

For selective measurement of hCG or free hCG $\beta$ or hCG $\beta$ cf certain epitope combinations can be suggested: for hCG (no recognition of hLH or noncombined subunits), a
$\mathrm{mAb}$ against epitope $c_{2}$ or $c_{3}$ can be combined with one against $\beta_{2 / 4}$ (Table 6). Alternatively, $\beta_{1}-\alpha_{3}$ combinations [66] or $\beta_{2 / 4}$ combined with a tracer mAb against an $\alpha$ epitope are possible [68]. These designs eliminate cross-reactions with free subunits but are sensitive to interferences by free subunits and hCG $\beta \mathrm{cf}$. For measurement of free hCG $\beta$, a $\mathrm{mAb}$ to epitope $\beta_{7}$ or $\beta_{14}$, and for hCG $\beta \mathrm{cf}$, a mAb to epitope $\beta_{11}$ can be combined with one to epitope $\beta_{2 / 4}$. For hCG $\alpha$, combinations of mAbs against epitopes $\alpha_{6}$ and $\alpha_{5}$ are recommended [69] (Table 6).

A unique mAb coded $\mathrm{B} 152$ is used for the measurement of hCG-h that carries a core-2 glycan on Ser132 located on hCG $\beta$ CTP [20]. However, the clinical utility of assays using this $\mathrm{mAb}$ remains to be established [70].

Future perspectives: harmonization of hCG and/or hCG $\beta$ and variant measurement

Considerable reduction in between-method and betweenlaboratory variability in results can be achieved by a number of measures: (1) the establishment and usage of a clear nomenclature of hCG and its variants [1,8]; (2) endorsement of that nomenclature to define what hCG-assay measure $[1,8,60]$; (3) characterization of diagnostic assays with the new six First IRRs calibrated in SI units that were adopted by WHO for immunoassay standardization [6]; (4) standardization of methods with the highly pure new WHO Fifth IS for hCG encoded $07 / 36,4$ which is identical to the First IRR for hCG 99/688; (5) harmonization of mAb epitopes used in diagnostic methods for hCG, hCG $\beta$, and their variants; and (6) the establishment of reference methods for the various forms of hCG [8], which will be supported by the detailed knowledge on $\mathrm{Ab}$ epitope recognition reported in the present study.

Acknowledgments We would like to thank the International Society of Oncology and BioMarkers for organizing the Tissue Differentiation (TD)-7 Workshop on hCG and Related Molecules, the International Federation of Clinical Chemistry (IFCC) Working Group for Standardization of hCG, the National Institute for Biological Standards and Control (NIBSC) (South Mimms, UK), and the National Hormone \& Peptide Program (NHPP), USA, for the supply of hormones and hormone variants. We would like to thank the following at Abbott Laboratories for their valued contributions: B.L. Dowell, S.Y. Tetin, and J.R. Fishpaugh. The NHS National Services Scotland, National Services Division, supported the work of Wilson Stewart. The Austrian Science Fund (National Research Network, S9307B05) in part supported the work of Peter Berger.

Open Access This article is distributed under the terms of the Creative Commons Attribution License which permits any use, distribution, and reproduction in any medium, provided the original author(s) and the source are credited. 


\section{Appendix}

Table 7 ISOBM-TD-7 Abs submitted to Dr. Kjell Nustad

\begin{tabular}{|c|c|c|c|c|}
\hline $\begin{array}{l}\text { ISOBMii } \\
\text { Ab Codes }\end{array}$ & Owner & Owner Codes & $\begin{array}{c}\text { ISOBMi\&ii } \\
\text { Codes }\end{array}$ & Controls \\
\hline 382 & Stenman & F16-6G5 & & \\
\hline 383 & Medix & 5501 SP-1 & & \\
\hline 384 & Stenman & F52-3F8 & & \\
\hline 385 & Medix & $5503 \mathrm{SPI}$ & & \\
\hline 386 & Stenman & F94-8F8 & & \\
\hline 387 & Medix & 5009 SP-5 & & \\
\hline 388 & Medix & 5006 SP-5 & & \\
\hline 389 & Stenman & \begin{tabular}{|l|l|l|l|l} 
\\
\end{tabular} & & \\
\hline 390 & Medix & 5008 SP-5 & & \\
\hline 391 & Medix & 6601 SPR-5 & & \\
\hline 392 & Stenman & F20-6E11 & & \\
\hline 393 & Stenman & F52-3C11 & & \\
\hline 394 & Medix & 5014 SPTN-5 & & \\
\hline 395 & Abbott & 71752 & & \\
\hline 396 & Stenman & F132-3C10 & & \\
\hline 397 & Stenman & F142-7F3 & & \\
\hline 398 & Stenman & F26-2G11 & & \\
\hline 399 & Stenman & F95-5C4 & & \\
\hline 400 & Abbott & 95658 & & \\
\hline 401 & Stenman & F95-1E8 & & \\
\hline 402 & Medix & 5004 SP-1 & & \\
\hline 403 & Roche & M-INN2 & $265,274,43$ & I.C. \\
\hline 404 & Stenman & F26-7E10 & & \\
\hline 405 & Stenman & F95-1B2 & & \\
\hline 406 & Medix & 5011 SPRN-1 & & \\
\hline 407 & Stenman & $\mathrm{F} 19-9 \mathrm{C} 11$ & & \\
\hline 408 & Medix & 5016 SPRN-5 & & \\
\hline 409 & Medix & 5012 SPRN-1 & & \\
\hline 410 & Roche & M-BCG005 & & \\
\hline 411 & Roche & M-1F7.9 & 275 & I.C. \\
\hline 412 & Siemens & $34 / 25.2 .2$ & & \\
\hline 413 & Mologic & D101 & & \\
\hline 414 & Paus & E26 & & \\
\hline 415 & Siemens & 3A11 & 281 & I.C. \\
\hline 416 & Paus & E30 & 273 & I.C. \\
\hline 417 & Roche & M-INN22 & 276.449 & I.C. \\
\hline 418 & Siemens & $2 \mathrm{~F} 11$ & 280 & I.C. \\
\hline 419 & Paus & E27 & 271 & I.C. \\
\hline 420 & Roche & M-94.139 & 277,264 & I.C. \\
\hline 421 & Siemens & $411 / 100.1 .1 .200$ & 0.4 .2 & \\
\hline 422 & Paus & E28 & 272 & I.C. \\
\hline 423 & Mologic & D102 & & \\
\hline 424 & Siemens & $1 \mathrm{G} 4$ & 279 & I.C. \\
\hline 425 & Siemens & $5 \mathrm{E} 5$ & & \\
\hline 426 & Siemens & $16 \mathrm{E} 2$ & & \\
\hline 427 & Siemens & 34A8.1.1 & & \\
\hline 432 & Medix & $41-3-9$ & & \\
\hline 433 & Medix & $45 \mathrm{~A} 10$ & & \\
\hline 428 sheep & Mologic & $8 F 11$ sheep & & \\
\hline 429 sheep & Mologic & 9F10 sheep & & \\
\hline 430 sheep & Mologic & 8 G5 sheep & & \\
\hline 431 sheep & Mologic & 618 sheep poly & & \\
\hline $434^{\mathrm{a}}$ & INN & hCG111 & & Ref \\
\hline $435^{\mathrm{a}}$ & INN & hCG2 & $265,274,40$ & Ref \\
\hline $436^{\mathrm{a}}$ & INN & hCG40 & & Ref \\
\hline $437^{a}$ & INN & hCG64 & & Ref \\
\hline $438^{a}$ & INN & hCG53 & & Ref \\
\hline $439^{a}$ & INN & hCG68 & & Ref \\
\hline $440^{a}$ & INN & hCG26 & & Ref \\
\hline $441^{\mathrm{a}}$ & INN & bLH1 & & Ref \\
\hline $442^{\mathrm{a}}$ & INN & hCG58 & & Ref \\
\hline $443^{\mathrm{a}}$ & INN & hCG112 & & Ref \\
\hline $444^{a}$ & INN & hCG106 & & Ref \\
\hline $445^{a}$ & INN & hCG24 & & Ref \\
\hline $446^{\mathrm{a}}$ & INN & hCG45 & & Ref \\
\hline $447^{\mathrm{a}}$ & INN & hCG10 & & Ref \\
\hline $448^{\mathrm{a}}$ & INN & hCG103 & & Ref \\
\hline $449^{a}$ & IINN & hCG22 & 276.417 & Ref \\
\hline $450^{\mathrm{a}}$ & Stahli & h54 & & Ref \\
\hline
\end{tabular}

I.C. Internal control

${ }^{a}$ Reference antibodies
Table 8 Abs grouped according to epitope recognition

\begin{tabular}{|c|c|c|c|c|c|}
\hline $\begin{array}{l}\text { ISOBMii } \\
\text { Ab Codes }\end{array}$ & Owner & Owner Codes & $\begin{array}{c}\text { ISOBMi\&ii } \\
\text { Codes }\end{array}$ & Controls & Epitope \\
\hline 403 & Roche & M-INN2 & $265,274,435$ & I.C. & $\beta_{1}$ \\
\hline $435^{a}$ & INN & hCG2 & $265,274,403$ & Ref & $\beta_{1}$ \\
\hline 382 & Stenman & F16-6G5 & & & \multirow{10}{*}{$\beta_{2}$} \\
\hline 388 & Medix & 5006 SP-5 & & & \\
\hline 390 & Medix & 5008 SP-5 & & & \\
\hline 402 & Medix & 5004 SP-1 & & & \\
\hline 408 & Medix & 5016 SPRN-5 & & & \\
\hline 416 & Paus & E30 & 273 & I.C. & \\
\hline 417 & Roche & M-INN22 & 276.449 & I.C. & \\
\hline 426 & Siemens & $16 \mathrm{E} 2$ & & & \\
\hline 427 & Siemens & $34 \mathrm{~A} 8.1 .1$ & & & \\
\hline $449^{a}$ & INN & hCG22 & 276.417 & Ref & \\
\hline 396 & $\begin{array}{l}\text { Stenman } \\
\end{array}$ & F132-3C10 & & & \multirow{8}{*}{$\beta_{3}$} \\
\hline 399 & Stenman & F95-5C4 & & & \\
\hline 400 & Abbott & 95658 & & & \\
\hline 401 & Stenman & F95-1E8 & & & \\
\hline 405 & Stenman & F95-1B2 & & & \\
\hline 423 & Mologic & D102 & & & \\
\hline $434^{a}$ & INN & hCG111 & & Ref & \\
\hline $441^{a}$ & INN & $\mathrm{bLH1}$ & & Ref & \\
\hline 419 & Paus & E27 & 271 & I.C. & \\
\hline $445^{\mathrm{a}}$ & INN & hCG24 & & Ref & $\beta_{4}$ \\
\hline 428 sheep & Mologic & $8 \mathrm{~F} 11$ sheep & & & \multirow{5}{*}{$\beta_{5}$} \\
\hline 429 sheep & Mologic & 9F10 sheep & & & \\
\hline 430 sheep & Mologic & 8G5 sheep & & & \\
\hline 431 sheep & Mologic & 618 sheep poly & & & \\
\hline $442^{a}$ & INN & hCG58 & & Ref & \\
\hline 410 & Roche & M-BCG005 & & & $\beta_{1}$ \\
\hline $437^{\mathrm{a}}$ & INN & hCG64 & & Ref & $\beta_{6}$ \\
\hline 386 & Stenman & |F94-8F8 & & & \multirow{6}{*}{$\beta_{7}$} \\
\hline 397 & Stenman & F142-7F3 & & & \\
\hline 407 & Stenman & F19-9C11 & & & \\
\hline 409 & Medix & 5012 SPRN-1 & & & \\
\hline 415 & Siemens & $3 \mathrm{~A} 11$ & 281 & I.C. & \\
\hline $439^{a}$ & INN & hCG68 & & Ref & \\
\hline $450^{\mathrm{a}}$ & Stahli & h54 & & Ref & \multirow{4}{*}{$\beta_{8}$} \\
\hline 395 & Abbott & 71752 & & & \\
\hline 413 & Mologic & D101 & & & \\
\hline 420 & Roche & M-94.139 & 277,264 & I.C. & \\
\hline 394 & Medix & 5014 SPTN-5 & & & \\
\hline 418 & Siemens & $2 \mathrm{~F} 11$ & 280 & I.C. & $\beta_{9}$ \\
\hline 392 & Stenman & F20-6E11 & & & \\
\hline 406 & Medix & 5011 SPRN-1 & & & $\beta$ \\
\hline 384 & Stenman & F52-3F8 & & & \multirow{5}{*}{$\beta c f$} \\
\hline 393 & Stenman & F52-3C11 & & & \\
\hline $443^{\mathrm{a}}$ & INN & hCG112 & & Ref & \\
\hline $444^{\mathrm{a}}$ & INN & hCG106 & & Ref & \\
\hline $448^{\mathrm{a}}$ & IINN & hCG103 & & Ref & \\
\hline 414 & Paus & E26 & & & \\
\hline $447^{a}$ & INN & hCG10 & & Ref & $c_{1}$ \\
\hline 387 & Medix & 5009 SP-5 & & & \multirow{6}{*}{$\mathrm{c}_{2}$} \\
\hline 411 & Roche & M-1F7.9 & 275 & I.C. & \\
\hline 422 & Paus & E28 & 272 & I.C. & \\
\hline 425 & Siemens & $5 \mathrm{E} 5$ & & & \\
\hline $436^{a}$ & INN & hCG40 & & Ref & \\
\hline $438^{\mathrm{a}}$ & INN & hCG53 & & Ref & \\
\hline $446^{a}$ & INN & hCG45 & & Ref & $c_{3}$ \\
\hline 424 & Siemens & $1 \mathrm{G} 4$ & 279 & I.C. & \\
\hline $440^{a}$ & INN & hCG26 & & Ref & $\mathrm{C}_{4}$ \\
\hline 389 & Stenman & F140-11C5 & & & \\
\hline 433 & Medix & $45 \mathrm{~A} 10$ & & & $\mathrm{C}$ \\
\hline 383 & Medix & 5501 SP-1 & & & \multirow{7}{*}{$\alpha$} \\
\hline 385 & Medix & 5503 SPI & & & \\
\hline 391 & Medix & 6601 SPR-5 & & & \\
\hline 398 & $\begin{array}{l}\text { Stenman } \\
\end{array}$ & F26-2G11 & & & \\
\hline 412 & Siemens & $34 / 25.2 .2$ & & & \\
\hline 421 & Siemens & $41 / 1 / 100.1 .1 .200$ & 0.4 .2 & & \\
\hline 432 & Medix & $41-3-9$ & & & \\
\hline 404 & Stenman & F26-7E10 & & & $\alpha_{6}$ \\
\hline
\end{tabular}




\section{References}

1. Berger P, Sturgeon C, Bidart JM, Paus E, Gerth R, Niang M, et al. The isobm td-7 workshop on hCG and related molecules. Towards user-oriented standardization of pregnancy and tumor diagnosis:assignment of epitopes to the three-dimensional structure of diagnostically and commercially relevant monoclonal antibodies directed against human chorionic gonadotropin and derivatives. Tumor Biol. 2002;23:1-38.

2. Stenman UH, Alfthan H, Hotakainen K. Human chorionic gonadotropin in cancer. Clin Biochem. 2004;37:549-61.

3. Lapthorn AJ, Harris DC, Littlejohn A, Lustbader JW, Canfield RE, Machin KJ, et al. Crystal structure of human chorionic gonadotropin. Nature. 1994;369:455-61.

4. Talmadge K, Boorstein WR, Fiddes JC. The human genome contains seven genes for the beta-subunit of chorionic gonadotropin but only one gene for the beta-subunit of luteinizing hormone. DNA. 1983;2:281-9.

5. Fiddes JC, Goodman HM. The cdna for the beta-subunit of human chorionic gonadotropin suggests evolution of a gene by readthrough into the 3'-untranslated region. Nature. 1980;286:684-7.

6. Sturgeon CM, Berger P, Bidart JM, Birken S, Burns C, Norman RJ, et al. Differences in recognition of the 1st who international reference reagents for hCG-related isoforms by diagnostic immunoassays for human chorionic gonadotropin. Clin Chem. 2009;55:1484-91.

7. Fiddes JC, Goodman HM. Isolation, cloning and sequence analysis of the cDNA for the alpha-subunit of human chorionic gonadotropin. Nature. 1979;281:351-6.

8. Stenman UH, Bidart JM, Birken S, Mann K, Nisula B, O'Connor J. Standardization of protein immunoprocedures. Choriogonadotropin (cg). Scand J Clin Lab Invest Suppl. 1993;216:42-78.

9. Birken S, Berger P, Bidart JM, Weber M, Bristow A, Norman R, et al. Preparation and characterization of new who reference reagents for human chorionic gonadotropin and metabolites. Clin Chem. 2003;49:144-54.

10. Merz WE, Krause JM, Roig J, Singh V, Berger P. Nonassembled human chorionic gonadotropin subunits and $\{$ alpha\} $\{$ alpha\}-homodimers use fast-track processing in the secretory pathway in contrast to \{alpha\} \{beta\}-heterodimers. Endocrinology. 2007;148:5831-41.

11. Valmu L, Alfthan H, Hotakainen K, Birken S, Stenman UH. Sitespecific glycan analysis of human chorionic gonadotropin betasubunit from malignancies and pregnancy by liquid chromatography-electrospray mass spectrometry. Glycobiology. 2006;16:120718.

12. Toll H, Berger P, Hofmann A, Hildebrandt A, Oberacher H, Lenhof $\mathrm{HP}$, et al. Glycosylation patterns of human chorionic gonadotropin revealed by liquid chromatography-mass spectrometry and bioinformatics. Electrophoresis. 2006;27:2734-46.

13. Wide L, Lee JY, Rasmussen C. A change in the isoforms of human chorionic gonadotropin occurs around the 13th week of gestation. J Clin Endocrinol Metab. 1994;78:1419-23.

14. Lopata A, Oliva K, Stanton PG, Robertson DM. Analysis of chorionic gonadotrophin secreted by cultured human blastocysts. Mol Hum Reprod. 1997;3:517-21.

15. Kovalevskaya G, Birken S, Kakuma T, Ozaki N, Sauer M, Lindheim $\mathrm{S}$, et al. Differential expression of human chorionic gonadotropin (hCG) glycosylation isoforms in failing and continuing pregnancies: preliminary characterization of the hyperglycosylated hCG epitope. J Endocrinol. 2002;172:497-506.

16. Mann K, Schneider N, Hoermann R. Thyrotropic activity of acidic isoelectric variants of human chorionic gonadotropin from trophoblastic tumors. Endocrinology. 1986;118:1558-66.

17. Berger P, Schwarz S, Spottl G, Wick G, Mann K. Variants of human chorionic gonadotropin from pregnant women and tumor patients recognized by monoclonal antibodies. J Clin Endocrinol Metab. 1993;77:347-51.
18. Lottersberger C, Hoermann R, Mann K, Schwarz S, Berger P. Tumor- and pregnancy-derived isoforms of human chorionic gonadotropin: biological and diagnostic relevance. Horm Res. 2003;59:125-34.

19. Elliott MM, Kardana A, Lustbader JW, Cole LA. Carbohydrate and peptide structure of the alpha- and beta-subunits of human chorionic gonadotropin from normal and aberrant pregnancy and choriocarcinoma. Endocrine. 1997;7:15-32.

20. Birken S. Specific measurement of o-linked core 2 sugarcontaining isoforms of hyperglycosylated human chorionic gonadotropin by antibody b152. Tumour Biol. 2005;26:131-41.

21. Bidart JM, Birken S, Berger P, Krichevsky A. Immunochemical mapping of hCG and hCG-related molecules. Scand J Clin Lab Invest Suppl. 1993;216:118-36.

22. Berger P, Bidart JM, Delves PS, Dirnhofer S, Hoermann R, Isaacs $\mathrm{N}$, et al. Immunochemical mapping of gonadotropins. Mol Cell Endocrinol. 1996;125:33-43.

23. Bidart JM, Troalen F, Bohuon CJ, Hennen G, Bellet DH. Immunochemical mapping of a specific domain on human choriogonadotropin using anti-protein and anti-peptide monoclonal antibodies. J Biol Chem. 1987;262:15483-9.

24. Dirnhofer S, Madersbacher S, Bidart JM, Ten Kortenaar PB, Spottl G, Mann K, et al. The molecular basis for epitopes on the free betasubunit of human chorionic gonadotrophin (hCG), its carboxylterminal peptide and the hCG beta-core fragment. J Endocrinol. 1994;141:153-62.

25. Kofler R, Kalchschmid E, Berger P, Wick G. Production and characterization of monoclonal antibodies against bovine luteinizing hormone. Immunobiology. 1981;160:196-207.

26. Kofler R, Berger P, Wick G. Monoclonal antibodies against human chorionic gonadotropin (hCG): I. Production, specificity, and intramolecular binding sites. Am J Reprod Immunol. 1982;2:212-6.

27. Stahli C, Miggiano V, Stocker J, Staehelin T, Haring P, Takacs B. Distinction of epitopes by monoclonal antibodies. Methods Enzymol. 1983;92:242-53.

28. Berger P. molecular morphology of placental and pituitary hormones: epitope mapping with monoclonal antibodies. Wien Klin Wochenschr. 1985;97:573-81.

29. Bidart JM, Bellet DH, Alberici GF, Van Besien F, Bohuon C. The immune response to a synthetic peptide analogous to the 109-145 beta hCG carboxyl-terminus is directed against two major and two minor regions. Mol Immunol. 1987;24:339-45.

30. Berger P, Panmoung W, Khaschabi D, Mayregger B, Wick G. Antigenic features of human follicle stimulating hormone delineated by monoclonal antibodies and construction of an immunoradiomometric assay. Endocrinology. 1988;123:2351-9.

31. Berger P, Klieber R, Panmoung W, Madersbacher S, Wolf H, Wick G. Monoclonal antibodies against the free subunits of human chorionic gonadotrophin. J Endocrinol. 1990;125:301-9.

32. Bidart JM, Ozturk M, Bellet DH, Jolivet M, Gras-Masse H, Troalen F, et al. Identification of epitopes associated with hCG and the beta hCG carboxyl terminus by monoclonal antibodies produced against a synthetic peptide. J Immunol. 1985;134:45764.

33. Bristow A, Berger P, Bidart JM, Birken S, Norman R, Stenman UH, et al. Establishment, value assignment, and characterization of new who reference reagents for six molecular forms of human chorionic gonadotropin. Clin Chem. 2005;51:177-82.

34. Tsai PK, Bruner MW, Irwin JI, Ip CC, Oliver CN, Nelson RW, et al. Origin of the isoelectric heterogeneity of monoclonal immunoglobulin h1b4. Pharm Res. 1993;10:1580-6.

35. Perkins M, Theiler R, Lunte S, Jeschke M. Determination of the origin of charge heterogeneity in a murine monoclonal antibody. Pharm Res. 2000;17:1110-7.

36. Madersbacher S, Berger P. Antibodies and immunoassays. Methods. 2000;21:41-50. 
37. Dirnhofer S, Lechner O, Madersbacher S, Klieber R, de Leeuw R, Wick G, et al. Free alpha subunit of human chorionic gonadotrophin: Molecular basis of immunologically and biologically active domains. J Endocrinol. 1994;140:145-54.

38. Schwarz S, Berger P, Wick G. The antigenic surface of human chorionic gonadotropin as mapped by murine monoclonal antibodies. Endocrinology. 1986;118:189-97.

39. Birken S, Krichevsky A, O'Connor J, Schlatterer J, Cole L, Kardana A, et al. Development and characterization of antibodies to a nicked and hyperglycosylated form of hCG from a choriocarcinoma patient: Generation of antibodies that differentiate between pregnancy hCG and choriocarcinoma hCG. Endocrine. 1999;10:137-44.

40. Novotny J, Handschumacher M, Haber E, Bruccoleri RE, Carlson WB, Fanning DW, et al. Antigenic determinants in proteins coincide with surface regions accessible to large probes (antibody domains). Proc Natl Acad Sci USA. 1986;83:226-30.

41. Charlesworth MC, Bergert ER, Morris JC, McCormick DJ, Ryan RJ. The antigenic structure of the human glycoprotein hormone alpha-subunit: Iii Solution- and solid-phase mapping using synthetic peptides. Endocrinology. 1991;128:2907-15.

42. Jackson AM, Klonisch T, Lapthorn AJ, Berger P, Isaacs NW, Delves PJ, et al. Identification and selective destruction of shared epitopes in human chorionic gonadotropin beta subunit. J Reprod Immunol. 1996;31:21-36.

43. Charrel-Dennis M, Jackson AM, Lund T, Lapthorn AJ, Berger P, Roitt $\mathrm{IM}$, et al. The major hormone-specific discontinuous epitopes on human chorionic gonadotrophin. J Mol Endocrinol. 2004;32:571-81.

44. Deshmukh US, Pal R, Talwar GP, Gupta SK. Antibody response against epitopes on hCG mapped by monoclonal antibodies in women immunized with an anti-hCG vaccine and its implications for bioneutralization. J Reprod Immunol. 1993;25:103-17.

45. Novotny J, Bruccoleri R, Newell J, Murphy D, Haber E, Karplus M. Molecular anatomy of the antibody binding site. J Biol Chem. 1983;258:14433-7.

46. Atassi MZ, Smith JA. A proposal for the nomenclature of antigenic sites in peptides and proteins. Immunochemistry. 1978;15:609-10.

47. Wu H, Lustbader JW, Liu Y, Canfield RE, Hendrickson WA. Structure of human chorionic gonadotropin at 2.6 a resolution from mad analysis of the selenomethionyl protein. Structure. 1994;2:545-58.

48. Schwarz S, Krude H, Klieber R, Dirnhofer S, Lottersberger C, Merz WE, et al. Number and topography of epitopes of human chorionic gonadotropin (hCG) are shared by desialylated and deglycosylated hCG. Mol Cell Endocrinol. 1991;80:33-40.

49. Birken S, Kovalevskaya G, O'Connor J. Metabolism of hCG and hLH to multiple urinary forms. Mol Cell Endocrinol. 1996;125:121-31.

50. Kovalevskaya G, Birken S, Kakuma T, O'Connor JF. Early pregnancy human chorionic gonadotropin (hCG) isoforms measured by an immunometric assay for choriocarcinoma-like hCG. J Endocrinol. 1999;161:99-106.

51. Birken S, Yershova O, Myers RV, Bernard MP, Moyle W. Analysis of human choriogonadotropin core 2 o-glycan isoforms. Mol Cell Endocrinol. 2003;204:21-30.

52. Cole LA, Sutton JM, Higgins TN, Cembrowski GS. Betweenmethod variation in human chorionic gonadotropin test results. Clin Chem. 2004;50:874-82.

53. Birken S, Armstrong EG, Kolks MA, Cole LA, Agosto GM, Krichevsky A, et al. Structure of the human chorionic gonadotropin beta-subunit fragment from pregnancy urine. Endocrinology. 1988;123:572-83.

54. Berger P, Sturgeon C. Human chorionic gonadotropin isoforms and their epitopes: diagnostic utility in pregnancy and cancer. Expert OpinMedDiagn. 2008;2:1347-64.

55. Dirnhofer S, Klieber R, De Leeuw R, Bidart JM, Merz WE, Wick G, et al. Functional and immunological relevance of the $\mathrm{COOH}$-terminal extension of human chorionic gonadotropin beta: implications for the who birth control vaccine. FASEB J. 1993;7:1381-5.
56. Hoermann R, Berger P, Spoettl G, Gillesberger F, Kardana A, Cole LA, et al. Immunological recognition and clinical significance of nicked human chorionic gonadotropin in testicular cancer. Clin Chem. 1994;40:2306-12.

57. Grenache DG, Greene DN, Dighe AS, Fantz CR, Hoefner D, McCudden C, et al. Falsely decreased human chorionic gonadotropin (hCG) results due to increased concentrations of the free beta subunit and the beta core fragment in quantitative hCG assays. Clin Chem. 2010;56:1839-44.

58. Madersbacher S, Berger P, Mann K, Kuzmists R, Wick G. Diagnostic value of free subunits of serum chorionic gonadotropin in testicular cancer. Lancet. 1990;336:630-1.

59. Lempiainen A, Stenman UH, Blomqvist C, Hotakainen K. Free beta-subunit of human chorionic gonadotropin in serum is a diagnostically sensitive marker of seminomatous testicular cancer. Clin Chem. 2008;54:1840-3.

60. Stenman UH, Tiitinen A, Alfthan H, Valmu L. The classification, functions and clinical use of different isoforms of hCG. Hum Reprod Update. 2006;12:769-84.

61. Marcillac I, Troalen F, Bidart JM, Ghillani P, Ribrag V, Escudier B, et al. Free human chorionic gonadotropin beta subunit in gonadal and nongonadal neoplasms. Cancer Res. 1992;52:3901-7.

62. Alfthan H, Haglund C, Roberts P, Stenman UH. Elevation of free beta subunit of human choriogonadotropin and core beta fragment of human choriogonadotropin in the serum and urine of patients with malignant pancreatic and biliary disease. Cancer Res. 1992;52:4628-33.

63. Alfthan H, Stenman UH. Pregnancy serum contains the beta-core fragment of human choriogonadotropin. J Clin Endocrinol Metab. 1990;70:783-7.

64. Norman RJ, Buck RH, Aktar B, Mayet N, Moodley J. Detection of a small molecular species of human chorionic gonadotropin in the urine of patients with carcinoma of the cervix and cervical intraepithelial neoplasia: comparison with other assays for human chorionic gonadotropin and its fragments. Gynecol Oncol. 1990;37:254-9.

65. O’Connor JF, Schlatterer JP, Birken S, Krichevsky A, Armstrong EG, McMahon D, et al. Development of highly sensitive immunoassays to measure human chorionic gonadotropin, its beta-subunit, and beta core fragment in the urine: application to malignancies. Cancer Res. 1988;48:1361-6.

66. Schwarz S, Berger P, Wick G. Epitope-selective, monoclonalantibody-based immunoradiometric assays of predictable specificity for differential measurement of choriogonadotropin and its subunits. Clin Chem. 1985;31:1322-8.

67. Klonisch T, Panayotou G, Edwards P, Jackson AM, Berger P, Delves PJ, et al. Enhancement in antigen binding by a combination of synergy and antibody capture. Immunology. 1996;89:16571.

68. Stenman UH, Alfthan H, Ranta T, Vartiainen E, Jalkanen J, Seppala M. Serum levels of human chorionic gonadotropin in nonpregnant women and men are modulated by gonadotropin-releasing hormone and sex steroids. J Clin Endocrinol Metab. 1987;64:730-6.

69. Madersbacher S, Klieber R, Mann K, Marth C, Tabarelli M, Wick $\mathrm{G}$, et al. Free alpha-subunit, free beta-subunit of human chorionic gonadotropin (hCG), and intact hCG in sera of healthy individuals and testicular cancer patients. Clin Chem. 1992;38:370-6.

70. Lempiainen A, Hotakainen K, Blomqvist C, Alfthan H, Stenman UH. Hyperglycosylated human chorionic gonadotropin in serum of testicular cancer patients. Clin Chem. 2012;58:1123-9.

71. Klonisch T, Delves PJ, Berger P, Panayotou G, Lapthorn AJ, Isaacs $\mathrm{NW}$, et al. Relative location of epitopes involved in synergistic antibody binding using human chorionic gonadotropin as a model. Eur J Immunol. 1996;26:1897-905.

72. Charrel-Dennis M, Terrazzini N, McBride JD, Kaye P, Martensen PM, Justesen J, et al. The human chorionic gonadotropin-beta arginine 68 to glutamic acid substitution fixes the conformation of the c-terminal peptide. Mol Endocrinol. 2005;19:1803-11. 